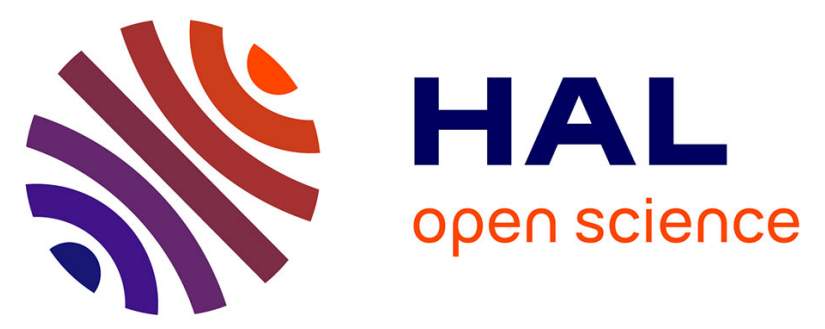

\title{
IFN-gamma activated JAK-1 shifts CD40-induced cytokine profiles in human antigen-presenting cells toward high IL-12p70 and low IL-10 production
}

Michael Conzelmann, Andreas H. Wagner, Anke Hildebrandt, Elena Rodionova, Michael Hess, Annika Zota, Thomas Giese, Christine S. Falk, Markus Hecker, Anthony D. Ho, et al.

\section{To cite this version:}

Michael Conzelmann, Andreas H. Wagner, Anke Hildebrandt, Elena Rodionova, Michael Hess, et al.. IFN-gamma activated JAK-1 shifts CD40-induced cytokine profiles in human antigen-presenting cells toward high IL-12p70 and low IL-10 production. Biochemical Pharmacology, 2010, 80 (12), pp.2074. 10.1016/j.bcp.2010.07.040 . hal-00637155

\section{HAL Id: hal-00637155 https://hal.science/hal-00637155}

Submitted on 31 Oct 2011

HAL is a multi-disciplinary open access archive for the deposit and dissemination of scientific research documents, whether they are published or not. The documents may come from teaching and research institutions in France or abroad, or from public or private research centers.
L'archive ouverte pluridisciplinaire HAL, est destinée au dépôt et à la diffusion de documents scientifiques de niveau recherche, publiés ou non, émanant des établissements d'enseignement et de recherche français ou étrangers, des laboratoires publics ou privés. 


\section{Accepted Manuscript}

Title: IFN-gamma activated JAK-1 shifts CD40-induced cytokine profiles in human antigen-presenting cells toward high IL-12p70 and low IL-10 production

Authors: Michael Conzelmann, Andreas H. Wagner, Anke Hildebrandt, Elena Rodionova, Michael Hess, Annika Zota,

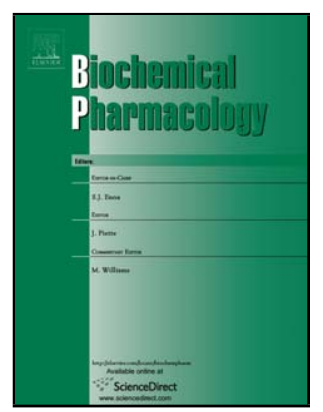
Thomas Giese, Christine S. Falk, Markus Hecker, Anthony D.

Ho, Peter Dreger, Thomas Luft

PII: $\quad$ S0006-2952(10)00578-2

DOI: $\quad$ doi:10.1016/j.bcp.2010.07.040

Reference: $\quad$ BCP 10673

To appear in: $\quad B C P$

Received date: $\quad 1-6-2010$

Revised date: $\quad 28-7-2010$

Accepted date: $\quad 29-7-2010$

Please cite this article as: Conzelmann M, Wagner AH, Hildebrandt A, Rodionova E, Hess M, Zota A, Giese T, Falk CS, Hecker M, Ho AD, Dreger P, Luft T, IFN-gamma activated JAK-1 shifts CD40-induced cytokine profiles in human antigen-presenting cells toward high IL-12p70 and low IL-10 production, Biochemical Pharmacology (2010), doi:10.1016/j.bcp.2010.07.040

This is a PDF file of an unedited manuscript that has been accepted for publication. As a service to our customers we are providing this early version of the manuscript. The manuscript will undergo copyediting, typesetting, and review of the resulting proof before it is published in its final form. Please note that during the production process errors may be discovered which could affect the content, and all legal disclaimers that apply to the journal pertain. 
IFN-gamma activated JAK-1 shifts CD40-induced cytokine profiles in human antigenpresenting cells toward high IL-12p70 and low IL-10 production

Michael Conzelmann*\#, Andreas H. Wagner ${ }^{\$}$, Anke Hildebrandt ${ }^{\$}$, Elena Rodionova*\#, Michael Hess*\#, Annika Zota*, Thomas Giese ${ }^{\Delta}$, Christine S. Falk ${ }^{\Delta}$, Markus Hecker ${ }^{\$}$, Anthony D. Ho ${ }^{\#}$, Peter Dreger ${ }^{\#}$, and Thomas Luft*\#

*From the German Cancer Research Center, Dept. of Molecular Oncology/Hematology, Heidelberg, " Dept. of Medicine V, University of Heidelberg, ${ }^{\$}$ Institute of Physiology and Pathophysiology, University of Heidelberg, and ${ }^{\Delta}$ National Center for Tumor Diseases and Institute of Immunology, University of Heidelberg, Germany.

Running title: $\quad$ CD40 and JAK1 in human APC

Key words: Dendritic cells, monocytes, B-cells, endothelial cells, CD40, CD40L, JAK, Tyk2, STAT, NF-кB, IRF-1, IRF-8, IL-12, IL-10

Word count: Abstract -194 words

Main text -4067 words

Corresponding author:

Thomas Luft, MD, PhD

University of Heidelberg

Dept. of Medicine V

Im Neuenheimer Feld 410

69120 Heidelberg, Germany

Tel. 49622156 8001, FAX 496221564920

Email: thomas.luft@med.uni-heidelberg.de 


\begin{abstract}
CD40Ligand (CD40L) represents a strong endogenous danger signal associated with chronic inflammatory disease. CD40L induces activation of antigen-presenting cells (APC) such as DCs, monocytes, B-cells and endothelial cells. However, CD40 activation alone, whilst inducing IL-10 production, is insufficient to induce interleukin (IL)-12p70 release in human APCs suggesting that additional cytokine signals (e.g. GM-CSF, IL-4 or IFN- $\gamma$ ) are required for the induction of a pro-inflammatory cytokine profile. We demonstrate that IFN- $\gamma$-induced Janus kinase 1 (JAK1) enhances CD40-induced IL-12p70 release whilst simultaneously inhibiting IL-10 synthesis, resulting in a pro-inflammatory phenotype of CD40L-activated dendritic cells (DCs). JAK2 mediated enhancing effects on IL-12p70 but did not inhibit IL-10 release, whereas Tyk 2 mediated inhibitory effects on IL-12p70 release in this system.

The mechanism by which complementary IFN- $\gamma / \mathrm{JAK}$ activities affect IL-12p70 production involves STAT1 activation and de novo induction of interferon-responsive factors (IRF)-1 and IRF-8. Simultaneously, JAK1 was unique in inhibiting IL-10 synthesis via STAT1 and IRF-8 with both transcription factors binding to the IL-10 promoter.

We demonstrate that CD40- and JAK/STAT/IRF-signalling pathways are strictly complementary for the induction of a pro-inflammatory cytokine profile in human APCs. This suggests that a number of CD40 effects in chronic inflammatory diseases might be weakened by targeting JAK/STAT.
\end{abstract}




\section{Introduction}

The CD40/CD40L system is increasingly recognized as a crucial cellular activation system of immune and non-immune cells. CD40 ligand (CD40L) induces pro-inflammatory activation of CD40-expressing antigen-presenting cells (APCs) such as dendritic cells (DCs), monocytes, B-cells and endothelial cells ${ }^{1}$. CD40 is a 45-50 $\mathrm{kDa}$ type I transmembrane protein with homology to the tumor necrosis factor (TNF) receptor ${ }^{2}$. In addition to its expression on the surface of immune cells such as B-cells, monocytes, macrophages and DCs, it is also found on non-immune cells such as epithelial and mesenchymal cells, haematopoietic progenitor cells, and platelets ${ }^{3}$. Activated endothelial cells also express CD40 together with numerous antigen-presenting features (MHC-I and -II, CD86, secretion of cytokines and chemokines), suggesting that endothelial cells are part of the antigen-presenting cell network that bridges innate and adaptive immunity ${ }^{4}$.

CD40L is a $39 \mathrm{kDa}$ type II transmembrane protein member of the TNF gene superfamily ${ }^{5}$. It is preferentially expressed on activated CD4+ T-cells and activated platelets, however, it can also be expressed on monocytes, macrophages, DCs, natural killer cells, B-cells, CD8+ Tcells, mast cells, basophils and even endothelial cells ${ }^{6,7}$. Following binding of CD40L, CD40 forms a trimer that triggers a signalling cascade involving binding to members of TRAFs (TNF receptor associated protein family), phosphorylation of cascades of kinases such as ERK, p38K and JNK and eventually leading to activation of transcription factors such as NF$\kappa \mathrm{B}, \mathrm{AP}-1$ and NFAT ${ }^{8}$. The best studied biological effect of CD40 signalling is the switch in recombination and synthesis of immunoglobulins by B-cells ${ }^{1,3}$. The CD40 pathway also plays a significant role in a variety of immune-mediated disorders such as inflammatory bowel disease ${ }^{6}$, systemic lupus erythematosus and rheumatoid arthritis ${ }^{9,10}$, acute and chronic graft versus host disease (GVHD) ${ }^{11}$, and various infectious diseases such as leprosy, leishmaniasis, and tuberculosis ${ }^{12}$.

Cytokine receptors are multi-subunit transmembrane complexes that utilize associated tyrosine kinases of the Janus kinases (JAK) and members of the signal transducer and activator of transcription (STAT) family of transcription factors for signal transduction. Four family members have been described for the JAKs that are differentially recruited to specific cytokine receptors. For instance, the IL-4 receptor has been reported to bind JAK1, JAK2, 
JAK3 and Tyk2 depending on the cell type studied ${ }^{13-16}$, whereas the GM-CSF receptor activates JAK2 and the IFN $\gamma$ receptor binds JAK 1 and JAK2 ${ }^{17}$.

We and others have reported that CD40L triggers pro-inflammatory differentiation of human monocyte-derived DCs. In particular, CD40L-induced IL-12p70 release is enhanced by cytokines such as IFN- $\gamma$, IL-4, IL-1 $\beta$ and IFN- $\alpha$, and inhibited by PGE2/cAMP ${ }^{18-24}$. Strength and persistence of the CD40L activation signal also modified DC differentiation ${ }^{25}$. Although the interactions between CD40L and cytokines such as IFN $\gamma$ and IL-4 in the activation of human DCs have been recognized, the molecular mechanism and specifically the influence of distinct JAK family members have not yet been analysed in this context. The capacity of IL-4 to induce the release of IL-12p70 (composed of a p35 and a p40 chain coupled by two disulfide bonds ${ }^{26}$ ) is especially remarkable, as IL-12p70 is known to be one of the strongest Th1-type cytokines inducing IFN $\gamma$ as well as cytotoxic maturation of NK-cells and cytotoxic T-lymphocytes (CTLs) ${ }^{26-28}$.

In this study we show that in a variety of human APCs, CD40L-induced IL-12p70 release strictly depends on complementary, cytokine-mediated JAK signalling. Performing siRNA knockdown studies on non-immortalized human cells, we define a so far unrecognized role for JAK1 (that was unique when compared to the other JAK family members) in the synthesis of both pro- and anti-inflammatory cytokines (IL-12p70 and IL-10). 


\section{Materials and Methods}

\section{Media}

Monocytes, DCs, peripheral mononuclear cells (PBMCs) and B-cells were cultured in complete medium: RPMI 1640 (Sigma-Aldrich, Taufkirchen, Germany) supplemented with $60 \mathrm{mg} / \mathrm{L}$ penicillin $\mathrm{G}, 12.6 \mathrm{mg} / \mathrm{L}$ streptomycin, $2 \mathrm{mM}$ L-glutamine, $1 \%$ nonessential amino acids, and $10 \%$ heat-inactivated fetal calf serum (FCS; Sigma-Aldrich) in a $5 \% \mathrm{CO}_{2}$ incubator.

Monoclonal antibodies, enzyme-linked immunosorbent assays (ELISA), cytokines, chemokines and inhibitors

Flow cytometric analyses of DCs were performed using the following monoclonal antibodies $(\mathrm{mAb})$ : fluorescein isothiocyanate (FITC)-conjugated $\mathrm{IgG}_{1}$ isotype control; phycoerythrin (PE)-conjugated $\mathrm{IgG}_{1}$ isotype control, PE-conjugated $\mathrm{IgG}_{2 \mathrm{a}}$ isotype control; antiCD86(B70/B7-2)-PE, anti-CD83-PE, anti-CD80(B7-1)-FITC, anti-HLA-A,B,C-FITC, antiHLA-DR-PE (BD Biosciences Pharmingen, Heidelberg, Germany). Cytokine ELISA kits (OptEIA) for IL-12p40, IL-12p70 and IL-10 were purchased from BD Pharmingen. The following cytokines were added to DC cultures: recombinant human (rh) GM-CSF (40 ng/ml, Berlex, Seattle, WA), rhIL-4 (50 U/ml; AL Immunotools, Friesoythe, Germany) and IFN $\gamma$ (1000 IU/ml; PromoCell, Heidelberg, Germany).

Cytokine secretion by stimulated MoDCs was measured by ELISA. IL-12p40, IL-12p70 and IL-10 ELISA were performed on supernatants of monocyte and MoDC cultures according to the manufacturer's instructions using Maxisorp plates (Nunc, Wiesbaden, Germany). The HRP substrate was tetramethylbenzidine (TMB) peroxidase (BD Pharmingen); the color reaction was terminated by adding $100 \mu \mathrm{l}$ sulphuric acid $(2 \mathrm{~N})$. Plates were read in a Sunrise microplate reader (Tecan, Salzburg, Austria).

\section{Cell culture}

PBMCs were obtained from buffy coat preparations of healthy donors from the Red Cross Blood Bank (IKTZ, Heidelberg, Germany) or from whole blood of healthy donors (after they had given their informed written consent) and used to produce MoDCs. CD14 ${ }^{+}$monocytes were affinity-purified using the MACS CD14 isolation kit (Miltenyi Biotech, BergischGladbach, Germany) and either activated immediately or cultured at $0.5-1 \times 10^{6}$ cells $/ \mathrm{mL}$ in culture medium supplemented with GM-CSF $(40 \mathrm{ng} / \mathrm{mL})$ and IL-4 $(50 \mathrm{U} / \mathrm{mL})$ in 24-well plates. By day 5-7, MoDCs represented more than 95\% of cultured cells. On day 5-7, cells 
were washed and readjusted to $2-3 \times 10^{5} \mathrm{DCs}$ per $\mathrm{mL}$ in cytokine-free medium. Isolation of human B-cells from whole blood of healthy donors was performed using the $\mathrm{CD} 14^{-}$flowthrough after $\mathrm{CD} 14^{+}$affinity purification. B-cells were isolated by magnetic depletion of nonB-cells (MACS B Cell Isolation Kit II, Miltenyi Biotech).

The BHK cell line expressing CD40L was a gift of Dr. E. Leo, Dept. of Haematology/Oncology, University of Heidelberg. Expression of CD40L was confirmed by flow cytometry using an anti-CD40L mAb (BD Pharmingen), whereas the mock-transfected control BHK cell line did not express CD40L. Mock-transfected BHK cells did not induce IL10 or IL-12p70 in human DC. The pan-JAK inhibitor I (Pyridone 6) (Calbiochem, Merck, Darmstadt, Germany) was titrated to define the maximal non-toxic concentration and added to the cell cultures 30 minutes prior to stimulation at a concentration of $500 \mathrm{nM}$.

\section{Human endothelial cells}

Human endothelial cells were isolated from umbilical cord veins (HUVECs) and cultured as described in detail elsewhere ${ }^{29}$; they were employed as a primary culture throughout. Briefly, cells were isolated from freshly collected umbilical cords by treatment with $1.6 \mathrm{U} / \mathrm{mL}$ dispase (Roche Diagnostics, Germany) for 30 minutes at $37^{\circ} \mathrm{C}$, and seeded into gelatin-coated 24-well plates in M199 medium containing 20\% fetal bovine serum (Invitrogen, Karlsruhe, Germany), $50 \mathrm{U} / \mathrm{ml}$ penicillin, $50 \mu \mathrm{g} / \mathrm{ml}$ streptomycin, $10 \mathrm{U} / \mathrm{ml}$ nystatin and endothelial cell growth supplement (Promocell, Heidelberg, Germany). They reached confluence and exhibited the typical "cobblestone" morphology after 5-6 days before commencing of the experiments. Primary HUVECs were essentially free of contaminating CD45+ $(<0.1 \%)$ or CD14+ $(<1.0 \%)$ leukocytes, as judged by FACS analysis. They were further identified by positive immunofluorescence for von Willebrand factor and negative immunofluorescence for smooth muscle $\alpha$-actin.

For co-incubation experiments $\left(24\right.$ and 48 hours at $37^{\circ} \mathrm{C}$ ) cells were seeded into gelatincoated 24-well plates (Greiner-Bio-One, Germany) and baby hamster kidney cells stably transfected with human CD40L (BHK-CD40L) or mock-transfected control cells were added both at $5 \times 10^{5}$ cells/well. As similar cytokine levels were measured in 24 and 48 hour cultures, only the results of the 24-hour time point are shown.

\section{Western blot analysis}

MoDCs activated for 1 hour with the indicated stimuli were harvested, washed, resuspended and lysed at a density of approx. $5 \times 10^{6}$ cells $/ \mathrm{mL}$ in Western Blot Sample Buffer (50mM Tris 
pH 7.5, 1\% BriJ 96V, $10 \mathrm{mM} \mathrm{NaF,} 1 \mathrm{mM}$ Na-orthovanadate, $1 \mu \mathrm{g} / \mathrm{ml}$ Leupetin, $1,5 \mu \mathrm{g} / \mathrm{ml}$ Pepstatin, $100 \mathrm{mM} \mathrm{PMSF}$ ) and snap frozen. Protein concentrations of the lysates were determined by a modified Bradford method (Bio-Rad Laboratories). Cell lysates were analysed by SDS-PAGE and Western blots as described previously ${ }^{25}$ using antibodies specific for phospho-JAK1, phospho-JAK2 (Cell Signaling, New England Biolabs, Frankfurt am Main, Germany), phospho-JAK3 (Santa Cruz Biotechnology, Heidelberg, Germany) and phospho-Tyk2 (Calbiochem), JAK1 (Chemicon, Millipore, Schwalbach, Germany), JAK2, JAK3 and Tyk2 (all from Cell Signaling), pSTAT1 (tyr701), pSTAT3 (tyr705) (Cell Signaling), IRF1 (sc-497, Santa Cruz Biotechnology), IRF-8 (Abnova GMBH, Heidelberg, Germany). For ECL based detection, Western blots were developed with ECL plus Western blot system (Santa Cruz Biotechnology) and the secondary HRP-conjugated antibodies goatanti-rabbit IgG or goat-anti-mouse IgG were used (Santa Cruz Biotechnology). For quantitative Western blot analysis, the Odyssey detecting system was used (LI-COR Biosciences, Bad Homburg, Germany). For detection, the secondary antibodies goat antimouse IRDye $680 \mathrm{~nm}$ and goat anti-rabbit IRDye $800 \mathrm{~nm}$ (both from LI-COR Biosciences) were used. Blots were imaged with the Odyssey infrared imager in both 700 and $800 \mathrm{~nm}$ channels in a single scan. Quantification was performed with the analysis software provided (Odyssey v2.1).

\section{DC electroporation}

For electroporation of MoDCs, a protocol adapted and modified from Prechtel et al. ${ }^{30}$ was used. Two strategies were applied: A) For constitutively expressed signalling proteins (JAKs, STATs, NEMO, NF- $\kappa$ B family members), DCs were harvested after 5 days of cultivation in IL-4 and GM-CSF, washed twice and resuspended in RPMI 1640 and $2 \times 10^{6}$ cells were transferred to a 4-mm cuvette (Bio-Rad Laboratories), $4.5 \mu \mathrm{g}$ siRNA was added and filled up with RPMI to a final volume of $200 \mu \mathrm{L}$. Cells were immediately pulsed in a GenePulser II (Bio-Rad Laboratories) with $300 \mathrm{~V}, 150 \mu \mathrm{F}, 100 \Omega$. Following electroporation, cells were rested in complete medium (no cytokines) for 24-48 hours. After rest, DC lysates were produced to control for transfection efficiency. The remaining cells were then activated for additional 36-48 hours and supernatants were collected afterwards to measure cytokine production. B) For proteins which are induced in response to DC activation (IL12p35, IL-10, IRF-1, IRF-8, NF- $\mathrm{B}$ family members), DCs were electroporated (using the above protocol) following the 24-48-hour rest period in cytokine-free medium and activated immediately after transfection. DCs lysates and supernatants were then collected 36-48 hours post activation. 
All siRNAs were purchased from Ambion (Austin, TX, USA). Electroporation was performed using the following siRNAs: human JAK1 218 (results shown), human JAK1 219, human JAK2 608, human JAK2 609 (results shown), human JAK3 42, human JAK3 43, human JAK3 44, human TYK2 399, human TYK2 400 (results shown), human IL12p35 144654, human IL-10 4019, human STAT1 s277, human STAT3 s743, human IRF-1 s7501, human IRF-8 s7100, silencer negative control. If available, validated siRNAs were used and at least 2 different types for the same target mRNA were tested.

\section{Real-Time RT-PCR quantification}

$2 \times 10^{6}$ cells were collected in $400 \mu \mathrm{L}$ lysis buffer from the MagnaPure mRNA Isolation Kit I (RAS, Mannheim, Germany) supplemented with 1\% (w/v) DTT, and mRNA was isolated with the MagnaPure-LC device using the mRNA-I standard protocol. The elution volume was set to $50 \mu \mathrm{L}$. An aliquot of $8.2 \mu \mathrm{L}$ RNA was reverse transcribed using AMV-RT and oligo(dT) as primer (First Strand cDNA synthesis kit, RAS) according to the manufacturer's protocol in a thermocycler. After termination of the cDNA synthesis, the reaction mix was diluted to a final volume of $500 \mu \mathrm{L}$ and stored at $-20^{\circ} \mathrm{C}$ until PCR analysis.

Primer sets specific for the sequences of IL-12p35, IL-12p40 and IL-10 optimized for the LightCycler (RAS) were developed and provided by SEARCH-LC GmbH, Heidelberg (www.search-lc.com). The PCR was performed with the LightCycler FastStart DNA SYBR Green I kit (RAS) according to the protocol provided in the parameter specific kits. To control for specificity of the amplification products, a melting curve analysis was performed. No amplification of unspecific products was observed. The copy number was calculated from a standard curve, obtained by plotting known input concentrations of four different plasmids at $\log$ dilutions to the PCR cycle number (CP) at which the detected fluorescence intensity reaches a fixed value. This approach dramatically reduced variations due to handling errors over several logarithmic dilution steps.

To correct for differences in the content of mRNA, the calculated copy numbers were normalized according to the average expression of two housekeeping genes, cyclophilin B and $\beta$-actin. Values were thus given as input adjusted copy number per $\mu \mathrm{L}$ of cDNA.

\section{Quantitative phospho-protein detection by the Luminex multiplex technology}

DCs were plated on 24 -well plates $\left(2 \times 10^{5} /\right.$ well $\left./ 1 \mathrm{~mL}\right)$ and activated for 1 hour as indicated in Figure 7A (control, CD40L, CD40L+IFN $\gamma$ ). Cells were then harvested and washed with PBS. Protein lysates were prepared adding cell lysis buffer with phenylmethylsulfonyl fluoride and 
protease inhibitors according to the manufacturer's instructions (Bio-Rad Laboratories) to the pellets. Phosphorylated as well as total protein were detected with a Bio-Rad phosphoprotein immunoassay kit using the Luminex 100 system and the BioPlex Manager 4.1.1 software. The

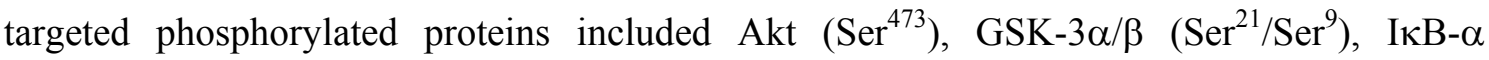
$\left(\operatorname{Ser}^{32} / \mathrm{Ser}^{36}\right), \mathrm{NF}-\kappa \mathrm{B}$ p65 (RelA) $\left(\operatorname{Ser}^{536}\right)$, Tyk2 $\left(\operatorname{Tyr}^{1054} / \mathrm{Tyr}^{1055}\right), \mathrm{ATF}-2\left(\mathrm{Thr}^{71}\right)$, c-Jun $\left(\operatorname{Ser}^{63}\right)$, ERK1/2 $\quad\left(\operatorname{Thr}^{202} / \operatorname{Tyr}^{204}, \quad \operatorname{Thr}^{185} / \operatorname{Tyr}^{187}\right), \quad \operatorname{HSP} 27 \quad\left(\operatorname{Ser}^{78}\right), \quad J N K \quad\left(\operatorname{Thr}^{183} / \operatorname{Tyr}^{185}\right), \quad$ MEK1 $\left(\operatorname{Ser}^{217} / \mathrm{Ser}^{221}\right)$, p38 MAPK $\left(\mathrm{Thr}^{180} / \mathrm{Tyr}^{182}\right)$, CREB $\left(\mathrm{Ser}^{133}\right)$. If available, total protein quantification was performed in a parallel assay (except for Tyk2, GSK-3 $\alpha / \beta$ and RelA). The assays were performed according to the manufacturer's instructions. Data acquisition and analysis were performed using Bio-Plex Manager software version 4.1.1, the data are represented as mean fluorescence intensity of 50 beads measured for each phosphorylated or total protein in each well.

\section{Electrophoretic mobility shift analysis (EMSA)}

Preparation of nuclear extracts from the cultured cells $(1 \mathrm{~h}$ and $6 \mathrm{~h}$ stimulation time) and subsequent non-denaturing $4 \%$ polyacrylamide gel electrophoresis were carried out as described previously ${ }^{4}$. The double-stranded gel shift oligonucleotides (Santa Cruz) for Sis-

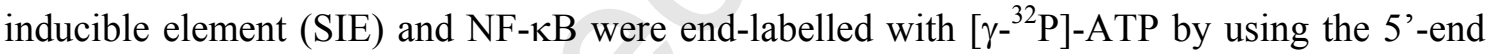
labelling kit from GE Healthcare, formerly Amersham Biosciences ${ }^{4}$. The specificity of the binding reaction was monitored by performing the assay in parallel with the same samples in the presence of a 100 fold excess of the non-labelled oligonucleotide ${ }^{4}$. For supershift analyses, the appropriate gel supershift antibody (STAT1 $\alpha$ p91, sc-591; STAT3, Sc-482; NFкB p65, sc-109; from Santa Cruz Biotechnology, Germany) and nuclear extracts were preincubated at ambient temperature for $60 \mathrm{~min}$ before the EMSA was performed. The sequence of the SIE gel shift ODN can bind STAT1/STAT1 homodimers, STAT1/STAT3 heterodimers as well as STAT3/STAT3 homodimers ${ }^{31,32}$. Band intensities were quantified by using the Quantity One 1-D Analysis Software (BioRad, Germany) after scanning of the autoradiograms with a Canon CanoScan 9900F scanner.

\section{Chromatin immune-precipitation (ChIP)}

ChIP assay was performed using a ChIP kit (17-295, Millipore) containing protein A agarose/salmon sperm DNA and all necessary buffers as described by the manufacturer. Cells were treated with $1 \%(\mathrm{v} / \mathrm{v})$ formaldehyde for $30 \mathrm{~min}$ at $37^{\circ} \mathrm{C}$ to cross-link proteins to the 
DNA. Afterwards cells were washed and lysed on ice. The chromatin was sheared by sonication (UP50H sonicator, Hielscher, Germany). One percent of the diluted cell supernatant was kept as the input material to quantify the DNA content of the samples. The supernatants were immunoprecipitated overnight at $4{ }^{\circ} \mathrm{C}$ with an antibody against IRF-8 (sc6058X from Santa Cruz Biotechnology) and mixed with protein A agarose/salmon sperm DNA. For a negative control a no-antibody immunoprecipition was performed in parallel. Following different washing steps the resulting immune complexes were resuspended in elution buffer and pooled. The cross-links were removed and the remaining protein was degraded by proteinase K treatment. DNA was isolated using the QiaQuick-PCR Purification Kit (Qiagen, Hilden, Germany) according to the manufacturer's instructions and used for the subsequent PCR analysis.

Amplification of the IL-10 promoter fragments (GenBank accession No. AF295024) was carried out by real-time PCR using the QuantiTect SYBR Green RT-PCR Kit (Qiagen) in a LightCycler instrument (Roche Diagnostics, Mannheim, Germany). Results were confirmed by conventional PCR (32 cycles) and agarose gel electrophoresis. The following primer pairs were used for the GAS elements: GAS1 (position 721-838) 5'GTGTTGGCATTCATGTCTCAG-3' (sense) and 5'CAAACAGGACTCCTATTTCTCAAG-3' (antisense); GAS2 (position 1864-1965) 5'GTAAGCACAAGGCAAGATG-3' (sense) and 5'-GAAGTGGACTCAGCATGG-3' (antisense); GAS3 (position 2899-2983) 5'-CCAAGACAACACTACTAAGGCTTC-3' (sense) and 5'-TGGAGGCTGGATAGGAGGTC-3' (antisense); GAS4 (position 3553-3646) 5'-AGGAGAAGTCTTGGGTATTCATC-3 (sense) 5'CAGTGACGTGGACAAATTGC-3' (antisense). The STAT1-ChIP analysis was performed by using the primer pair and anti-STAT1 antibody (sc-346X, Santa Cruz Biotechnology) as previously described ${ }^{33}$. PCR signals obtained from the immunoprecipitated DNA were visualized and analyzed with a GelDoc ${ }^{\mathrm{TM}}$ XR molecular imager and the Quantity One 1-D analysis software (BioRad, Munich, Germany). Signals from the control IgG antibody were subtracted from the PCR signals and normalized relative to the signals of nonimmunoprecipitated input DNA.

\section{Bioinformatic analysis}

Analysis of the human IL-10 promoter (GenBank accession No. AF295024) for potential STAT1 and GAS consensus sequences was performed by using the MatInspector tool provided by Genomatix (Munich, Germany). The small palindromic consensus sequence 
$\mathrm{TTCN}^{2-4}$ GAA (for review see ${ }^{34}$ ) that defines a GAS element was identified by manual inspection at positions 789-797, 1963-1970, 2914-2924 and 3616-3623 upstream of the transcription start site.

\section{Statistical analyses}

Statistical analyses were performed using the paired Student's t-test with a p-value of 0.05 or less considered significant. Standard errors of the mean (SEM) were calculated if the mean of replicate samples of the same blood donor was used to calculate the mean value of all donors (ELISAs). Standard deviations (SD) were calculated if single data points of each donor were used to calculate the means of all donors (Western blots, RT-PCR). 


\section{Results}

CD40L-induced IL-12p70 release requires complementary cytokine signalling in human DCs MoDCs are generated by culturing CD14 $4^{+}$monocytes for 5-7 days in GM-CSF and IL-4 (GM/IL4) and produce high levels of IL-12p70 in response to CD40L (similarly when CD40L was provided as a soluble trimer or expressed on the cell surface of a BHK cell line) ${ }^{21}$. We and others have shown that IL-4 can enhance CD40L-induced IL-12p70 release from human and murine DCs ${ }^{18}$. We therefore examined if the presence of IL-4 and GM-CSF is required for the cytokine induction by CD40L. In fact, when MoDCs were washed and rested (w\&r) for 48 hours in cytokine-free medium, their capacity to release IL-12p70 in response to CD40L was virtually lost (Figure 1A). Similarly, non-toxic concentrations of a pan-JAK inhibitor (Pyridone 6) completely blocked release of IL-12p70 from MoDCs conventionally activated with CD40L (without w\&r) (Figure 1A). Re-exposure to GM/IL4 restored the cytokine synthesizing capacity in w\&r MoDCs (Figure 1B). Both GM-CSF and IL-4 had significant effects on their own and synergized when added together, whereas IFN- $\gamma$ was the strongest inducer of IL-12p70 release after 24-36 hours activation (Figure 1B). The pan-JAK inhibitor completely abrogated IL-12p70 release induced by CD40L plus any of these cytokines (IL-4, GM-CSF/IL-4 or IFN- $\gamma$ ) (Figure 1C).

Activity and function of individual JAK family members

The functional contribution of the different JAK family members to the formation of IL12 p70 was studied using siRNA targeting the different JAKs. We were capable of reducing protein expression of one specific JAK family member without influencing expression of the others 48 hours after electroporation of the siRNA (Figure 2A and E). Electroporation reduced viability by $20 \%$, however, no differences in viability were found between negative control siRNA (=scrambled (scr) siRNA)) and the JAK-specific siRNAs. Activation of MoDCs with CD40L plus cytokines 48 hours post-siRNA transfection demonstrated that JAK1 and JAK2 enhance whereas Tyk2 inhibits IL-12p70 release (Figure 2 B-D). No significant effects were observed using three different JAK3-siRNAs (Figure 2F).

\section{Reciprocal regulation of IL-12p70 and IL-10 formation by IFN- $\gamma / J A K 1$}

In response to $\mathrm{CD} 40 \mathrm{~L}$ activation alone, w\&r MoDCs produced little or no IL-12p70 (see above), but significant levels of IL-10 (Figure 3A). Activation of w\&r MoDCs with CD40L in combination with IL-4, GM/IL4 or IFN $\gamma$ significantly reduced IL-10 release (Figure 3A). 
This effect was mediated at least in part by the JAK/STAT pathway, as the pan-JAK inhibitor reversed the inhibitory effect of IFN $\gamma$ on IL-10 release (Figure 3B). Similarly, JAK1 siRNA (Figure 3C) (but not JAK2, JAK3 or Tyk2 siRNA enhanced IL-10 release from CD40L plus IFN $\gamma$-activated MoDCs. These data demonstrate that IFN- $\gamma / \mathrm{JAK} 1$ activation reciprocally influences CD40L-induced pro- and anti-inflammatory cytokines by enhancing IL-12p70 and inhibiting IL-10 formation.

One possible mechanism of this reciprocal regulation might be inhibition of an autocrine feedback loop, as IL-10 is known to reduce IL-12p70 release. Indeed, titration of the pan-JAK inhibitor revealed that IL-12p70 levels drop to a similar degree as IL-10 levels rise (Figure 3D). However, when directly suppressing IL-10 synthesis by using siRNA for IL-10, we observed that although IL-10 abundance was strongly suppressed, there was no effect on IL12 p70 release in DCs activated with CD40L plus IFN- $\gamma$ (Figure 3E). In contrast, a significant but mild increase of IL-12p70 was observed in DCs transfected with IL-10 siRNA and activated with CD40L only (Figure 3F). Therefore, autocrine feedback loops appear to play a minor role in the reciprocal regulation of IL-12p70 and IL-10 synthesis by JAK1.

IFN- $/$ JAK1 effects on IL-12p70 and IL-10 synthesis are mediated by STAT1, IRF-1 and IRF8 regulating $m R N A$ transcription

Exploring the effects of siRNAs for STAT1, STAT2, STAT3, STAT4, STAT5 and STAT6, we found that only STAT1 siRNA reduced IL-12p70 production whilst enhancing IL-10 formation (Figure 4A). Therefore, STAT1 appears to be the target transcription factor regulated by the panJAK inhibitor and JAK1 siRNA (see Figures 1C, 2B and 3C). In contrast, STAT3 siRNA did not affect IL-12p70 but reduced IL-10 production in this experimental setting (Figure 4A). Moreover, siRNA knockdown of STAT2, STAT4, STAT5 and STAT6 did neither influence IL-12p70 nor IL-10 formation ( $\mathrm{n}=4$, data not shown).

STAT1 effects on IL-12 transcription are mediated by interferon-regulated factors 1 and 8 forming heterodimers at the IL-12p35 promoter ${ }^{35,36}$. Indeed, siRNA for both, IRF-1 and IRF8 strongly inhibited IL-12p70 release (Figure 4B). Interestingly with regard to IL-10 it was IRF-8 but not IRF-1 siRNA treatment that enhanced IL-10 release (Figure 4B), suggesting that IL-10 gene expression is not regulated by IRF-1/8 heterodimers as is IL-12p35.

Direct binding of STAT1 to the IL-10 promoter has recently been shown for the human RPMI-8826.1 B-cell line ${ }^{33}$, however this has not been reported so far for non-immortalized cells. Performing ChIP analyses with human DC lysates we observed JAK-dependent binding 
of STAT1 to an IL-10 promoter fragment containing the STAT binding site at position -120 (Figure 4C).

In contrast, IRF-8-mediated inhibition of IL-10 expression has not been reported so far. Performing ChIP analyses of 4 GAS sites that cover a large section of the IL-10 promoter (GAS1 (position -721 to -838), GAS2 (position -1864 to -1965), GAS3 (position -2899 to -2983) and GAS4 (position -3553 to -3646)), we demonstrate IFN- $\gamma$-dependent recruitment of IRF-8 to the IL-10 promoter region containing GAS sites number 2 and 3 (Figure 4D), suggesting that IRF-8 binds in a direct or indirect manner to the IL-10 promoter.

STAT1, IRF1 and IRF8 regulate mRNA expression. Figure $4 \mathbf{E}$ in fact substantiates that IL12 p35 and IL-10 mRNA expression are transcriptionally regulated by CD40L and IFN- $\gamma$ whereas IL-12p40 was induced by CD40L alone.

JAK/STAT is the major CD40-complementing pathway induced by IFN- $\gamma$

Complementary activity of CD40 and cytokine-induced signalling was investigated in w\&r MoDCs activated with CD40L and/or IFN- $\gamma$. Complementary CD40- and IFN- $\gamma$-dependent STAT1 and NF- $\kappa$ B signalling could be demonstrated upon examining DNA-binding activities of both transcription factors in MoDC nuclear extracts by electrophoretic mobility shift analysis. STAT1-binding activity was exclusively found in the presence of IFN- $\gamma$ (Figure 5A,C,E), whereas NF-кB-p65 activity was observed with CD40L alone as well as with the combination of CD40L plus IFN- $\gamma($ Figure 5B,D). These results demonstrate that induction of non-overlapping, complementary CD40 (p65) and cytokine (JAK/STAT) signalling correlates with the release of IL-12p70. Similarly, early induction of IRF-1 and IRF-8 expression was inefficient with CD40L alone and also depended on additional IFN- $\gamma$ (Figures 5F,G).

Does phosphorylation of JAK/STAT represent the only complementary effect of cytokine signalling on CD40L activation? Performing phosphoplex analyses of DC lysates 1 hour following activation we observed that CD40L alone was sufficient to induce maximum phosphorylation of all signalling pathways examined (CREB, MEK1, ERK1/2, p38K, JNK, Akt-1, GSK-3 (Ser), NFкB-p65 and $\mathrm{I} \kappa \mathrm{B} \alpha$ ) with no enhancing effects of additional IFN $\gamma$ (Figure 5H). Total protein concentrations were not different in the lysates with the exception of $\mathrm{I} \kappa \mathrm{B} \alpha$ that was degraded in CD40L-activated MoDCs (Figure 5I).

These results suggest that JAK/STAT activation is the major, CD40-complementing effect of cytokines after 1 hour of stimulation. 
JAK dependent IL-12p70 production by human APCs

We next examined whether the strict need of complementary CD40 and JAK/STAT signalling for pro-inflammatory activation is a general characteristic of CD40-expressing APCs. In fact, when exposing human monocytes, human B-cells, or human umbilical vein endothelial cells (HUVECs) to CD40L and/or cytokines, significant release of IL-12p70 was observed only in the presence of both, CD40L and one of the cytokines IFN $\gamma$, IL-4 or GM/IL4 (Figures 6 AC). As in DCs, the pan-JAK inhibitor virtually abolished IL-12p70 secretion in all cell types studied (Figure 6D). This demonstrates that JAK/STAT activation generally enhances IL12 p70 production in human APCs activated with CD40L plus cytokines. 


\section{Discussion}

This study defines a specific role for JAK1 as compared to the other JAK family members in complementing a CD40 signal for the induction of a pro-inflammatory phenotype (high IL12 p70 - low IL-10) of human APCs. We further show that the strict requirement of complementary CD40 and JAK/STAT signalling for IL-12p70 release is a common feature of human CD40-expressing APCs, including DCs, monocytes, B-cells and endothelial cells. We performed successful siRNA knockdown studies of all JAK/STAT family members and of IRF1 and IRF8 using human DC that represent a non-proliferating, non-immortalized cell population. Our results show that although CD40L alone is capable of inducing phenotypic DC maturation and cytokine production including high levels of IL-10, IL-12p70 protein synthesis required simultaneous activation of JAK1 or JAK2. This requirement of a "second signal" for a full pro-inflammatory activation might serve as an additional point of control for the immune system. If CD40 and CD40L are expressed at the site of inflammation, IL-12p70 will only be released in the case of additional cytokine-mediated JAK activation.

The mechanism of IFN- $\gamma /$ JAK1/2-induced IL-12 expression involves STAT1 phosphorylation and induction of both IRF-1 and IRF-8 expression. IRF-1 was shown to be involved in IL12 p35 transcription ${ }^{30,31}$. IRF-8 was reported to physically interact with IRF-1 at the IRF-E site in the promoter of the IL-12p35 gene enhancing its transcription ${ }^{35,36}$. We found that IRF1 and IRF-8 expression in MoDCs was in fact rapidly induced by CD40L plus IFN $\gamma$ (but not by CD40L alone), and siRNA for IRF-1 and IRF-8 strongly inhibited IL-12p70 release. Although transcriptional regulation of cytokine mRNA is clearly one mechanism of the complementary IFN- $\gamma / \mathrm{JAK} 1 / \mathrm{STAT} 1 / \mathrm{IRF}-1 / \mathrm{IRF}-8$ and CD40 signalling, additional mechanisms such as mRNA stabilization cannot be excluded.

With regard to IL-10, our study shows for the first time that IFN- $\gamma$ mediated inhibition of IL10 expression is a specific characteristic of JAK1 and involves direct binding of STAT1 as well as direct or indirect binding of IRF-8 to the promoter of the IL-10 gene. Interestingly, although JAK1 and STAT1 both inhibited IL-10 expression, this effect was not mediated by IRF-1. In contrast, siRNA inhibition of IRF-8 mimicked the effects of JAK1 and STAT1 inhibition on both IL-12p70 and IL-10 production, arguing for a common and so far unrecognized IFN- $\gamma /$ JAK1/STAT1/IRF-8 pathway. IRF-8 itself has only weak DNA binding affinity ${ }^{37,38}$. However, the binding of IRF-8 to DNA is dramatically increased following 
interaction with IRF-1, IRF2- or Ets-like transcription factors ${ }^{38,39}$. Although it remains open which cofactors are involved and what the exact binding sequence might be, we provide evidence that IRF-8 binds to the promoter of the human IL-10 gene.

Although JAK1 and JAK2 both enhanced IL-12p70 secretion as shown by siRNA knockdown, enhanced IL-10 production was only observed with JAK1-siRNA. The weak IL-4 mediated phosphorylation of JAK1 and JAK2 (as compared with IFN- $\gamma$ ) suggests that the combined synergistic activities of both JAK1 and JAK2 can mediate IL-4-stimulated IL12p70 secretion. However, IL-4-induced JAK1 activity alone may be too weak to fully activate the inhibitory JAK1/STAT1/IRF-8 pathway. Alternatively, we cannot exclude additional, JAK-independent mechanisms that differentially regulate IL-10 production in response to IL-4.

The distinct characteristics of the JAK family members on IL-12p70 (JAK1 and JAK2 both enhance, Tyk2 inhibits) and IL-10 (JAK1 alone inhibits) again underline the functional complexity of these pathways. Cytokines activate distinct sets of JAK /STAT family members in a cell type-specific manner. The net outcome of a type I interferon signal for instance (activating JAK1 and Tyk2) is hard to predict and might depend on the intracellular context (such as the preceding signal transduction history of the cell). Indeed, controversial results have been reported as to how type I interferons influence IL-12p70 production ${ }^{40,41}$. Similarly, IL-4, a Th-2-inducing cytokine, has been reported to enhance IL-12p70 release in a variety of human APCs in vitro ${ }^{18}$. The undeniable but ill-defined presence of other cytokines and cytokine networks in vivo but also in vitro (e.g. in fetal bovine serum or autocrine cytokines of the cells in culture) will pose a caveat to conclusions of what a specific cytokine "does" to a defined cell type. In contrast, interfering with JAK signalling will target the first common denominators of most cytokine signals and therefore has promise for clinical applications.

In summary, our results support the concept that JAK1 and JAK2 signalling directly influence the cytokine panel of a CD40L-induced immune response. This suggests that the in vivo use of JAK inhibitors might indirectly modulate the effects of CD40 signalling on a global scale. In particular IFN- $\gamma$-induced JAK1 is enhancing IL-12p70 and inhibiting IL-10 release and therefore represents a promising target for immunosuppressive strategies. Although specific JAK1 inhibitors have not been reported as yet, the high resolution crystal structure of the 
active form of the JAK1 PTK domain has been reported ${ }^{42}$ and oral JAK1/2 inhibitors (e.g. INCB18424) are already under clinical investigation. 


\section{Acknowledgments}

This work was supported by grants from the Deutsche Forschungsgemeinschaft (LU830/2, SFB 405 project B17), and the Tumorzentrum Heidelberg-Mannheim. We thank Dr. HannsMartin Lorenz for helpful comments and the revision of the manuscript.

\section{Author contributions}

MC was involved in the design of the experimental procedures, in performing part of the experimental procedures, in the evaluation of the data and in the writing of the manuscript.

AW and AH provided the endothelial cell cultures, performed the EMSAs and ChIP assays, contributed ideas and were involved in the writing of the manuscript.

ER was involved in the design of parts of the experimental procedures and in performing these.

MHess and AZ performed experiments.

CSF performed the Multiplex analyses.

TG performed real time PCR analyses.

SB performed experimental procedures and contributed ideas and helped in writing of the manuscript.

MHecker and PD contributed ideas, critically evaluated the data and were involved in the writing of the manuscript.

TL planned the study, was involved in designing the experiments, evaluating the results and writing of the manuscript.

\section{Conflicts of interest}

We have no conflicts of interest to declare. 


\section{Reference List}

(1) van Kooten C, Banchereau J. CD40-CD40 ligand. J Leukoc Biol. 2000;67:2-17.

(2) Smith CA, Farrah T, Goodwin RG. The TNF receptor superfamily of cellular and viral proteins: activation, costimulation, and death. Cell. 1994;76:959-962.

(3) Schonbeck U, Libby P. The CD40/CD154 receptor/ligand dyad. Cell Mol Life Sci. 2001;58:4-43.

(4) Wagner AH, Gebauer M, Pollok-Kopp B, Hecker M. Cytokine-inducible CD40 expression in human endothelial cells is mediated by interferon regulatory factor-1. Blood. 2002;99:520-525.

(5) Lederman S, Yellin MJ, Krichevsky A et al. Identification of a novel surface protein on activated CD4+ $\mathrm{T}$ cells that induces contact-dependent B cell differentiation (help). J Exp Med. 1992;175:1091-1101.

(6) Danese S, Sans M, Fiocchi C. The CD40/CD40L costimulatory pathway in inflammatory bowel disease. Gut. 2004;53:1035-1043.

(7) Wagner AH, Guldenzoph B, Lienenluke B, Hecker M. CD154/CD40-mediated expression of CD154 in endothelial cells: consequences for endothelial cell-monocyte interaction. Arterioscler Thromb Vasc Biol. 2004;24:715-720.

(8) Grammer AC, Lipsky PE. CD40-mediated regulation of immune responses by TRAF-dependent and TRAF-independent signaling mechanisms. Adv Immunol. 2000;76:61-178.

(9) Crow MK, Kirou KA. Regulation of CD40 ligand expression in systemic lupus erythematosus. Curr Opin Rheumatol. 2001;13:361-369.

(10) Lee HY, Jeon HS, Song EK et al. CD40 ligation of rheumatoid synovial fibroblasts regulates RANKLmediated osteoclastogenesis: evidence of NF-kappaB-dependent, CD40-mediated bone destruction in rheumatoid arthritis. Arthritis Rheum. 2006;54:1747-1758.

(11) Prigozhina TB, Gurevitch O, Elkin G et al. CD40 ligand-specific antibodies synergize with cyclophosphamide to promote long-term transplantation tolerance across MHC barriers but inhibit graft-vs-leukemia effects of transplanted cells. Exp Hematol. 2003;31:81-88.

(12) Chamekh M. CD40-CD40L Interaction in Immunity Against Protozoan Infections. J Biomed Biotechnol. 2007;2007:59430.

(13) Murata T, Noguchi PD, Puri RK. Receptors for interleukin (IL)-4 do not associate with the common gamma chain, and IL-4 induces the phosphorylation of JAK2 tyrosine kinase in human colon carcinoma cells. J Biol Chem. 1995;270:30829-30836.

(14) Nelms K, Huang H, Ryan J, Keegan A, Paul WE. Interleukin-4 receptor signalling mechanisms and their biological significance. Adv Exp Med Biol. 1998;452:37-43.

(15) Welham MJ, Learmonth L, Bone H, Schrader JW. Interleukin-13 signal transduction in lymphohemopoietic cells. Similarities and differences in signal transduction with interleukin-4 and insulin. J Biol Chem. 1995;270:12286-12296.

(16) Witthuhn BA, Silvennoinen O, Miura O et al. Involvement of the Jak-3 Janus kinase in signalling by interleukins 2 and 4 in lymphoid and myeloid cells. Nature. 1994;370:153-157.

(17) Baker SJ, Rane SG, Reddy EP. Hematopoietic cytokine receptor signaling. Oncogene. 2007;26:67246737.

(18) Hochrein H, O'Keeffe M, Luft T et al. Interleukin (IL)-4 is a major regulatory cytokine governing bioactive IL-12 production by mouse and human dendritic cells. J Exp Med. 2000;192:823-833. 
(19) Kalinski P, Hilkens CM, Snijders A, Snijdewint FG, Kapsenberg ML. IL-12-deficient dendritic cells, generated in the presence of prostaglandin E2, promote type 2 cytokine production in maturing human naive T helper cells. J Immunol. 1997;159:28-35.

(20) Kalinski P, Smits HH, Schuitemaker JH et al. IL-4 is a mediator of IL-12p70 induction by human Th2 cells: reversal of polarized Th2 phenotype by dendritic cells. J Immunol. 2000;165:1877-1881.

(21) Luft T, Jefford M, Luetjens P et al. Functionally distinct dendritic cell (DC) populations induced by physiologic stimuli: prostaglandin $\mathrm{E}(2)$ regulates the migratory capacity of specific DC subsets. Blood. 2002;100:1362-1372.

(22) Luft T, Luetjens P, Hochrein H et al. IFN-alpha enhances CD40 ligand-mediated activation of immature monocyte-derived dendritic cells. Int Immunol. 2002;14:367-380.

(23) Luft T, Jefford M, Luetjens P et al. IL-1 beta enhances CD40 ligand-mediated cytokine secretion by human dendritic cells (DC): a mechanism for T cell-independent DC activation. J Immunol. 2002;168:713-722.

(24) Snijders A, Kalinski P, Hilkens CM, Kapsenberg ML. High-level IL-12 production by human dendritic cells requires two signals. Int Immunol. 1998;10:1593-1598.

(25) Luft T, Maraskovsky E, Schnurr M et al. Tuning the volume of the immune response: strength and persistence of stimulation determine migration and cytokine secretion of dendritic cells. Blood. 2004;104:1066-1074.

(26) Zhang S, Wang Q. Factors determining the formation and release of bioactive IL-12: regulatory mechanisms for IL-12p70 synthesis and inhibition. Biochem Biophys Res Commun. 2008;372:509-512.

(27) Paunovic V, Carroll HP, Vandenbroeck K, Gadina M. Signalling, inflammation and arthritis: crossed signals: the role of interleukin (IL)-12, -17, -23 and -27 in autoimmunity. Rheumatology (Oxford). 2008;47:771-776.

(28) Weiss JM, Subleski JJ, Wigginton JM, Wiltrout RH. Immunotherapy of cancer by IL-12-based cytokine combinations. Expert Opin Biol Ther. 2007;7:1705-1721.

(29) Lienenluke B, Germann T, Kroczek RA, Hecker M. CD154 stimulation of interleukin-12 synthesis in human endothelial cells. Eur J Immunol. 2000;30:2864-2870.

(30) Prechtel AT, Turza NM, Theodoridis AA, Kummer M, Steinkasserer A. Small interfering RNA (siRNA) delivery into monocyte-derived dendritic cells by electroporation. J Immunol Methods. 2006;311:139-152.

(31) Korzus E, Nagase H, Rydell R, Travis J. The mitogen-activated protein kinase and JAK-STAT signaling pathways are required for an oncostatin M-responsive element-mediated activation of matrix metalloproteinase 1 gene expression. J Biol Chem. 1997;272:1188-1196.

(32) Mynard V, Guignat L, Devin-Leclerc J, Bertagna X, Catelli MG. Different mechanisms for leukemia inhibitory factor-dependent activation of two proopiomelanocortin promoter regions. Endocrinology. 2002;143:3916-3924.

(33) Schaefer A, Unterberger C, Frankenberger M et al. Mechanism of interferon-gamma mediated downregulation of interleukin-10 gene expression. Mol Immunol. 2009;46:1351-1359.

(34) Decker T, Kovarik P, Meinke A. GAS elements: a few nucleotides with a major impact on cytokineinduced gene expression. J Interferon Cytokine Res. 1997;17:121-134.

(35) Jayakumar A, Donovan MJ, Tripathi V, Ramalho-Ortigao M, McDowell MA. Leishmania major infection activates NF-kappaB and interferon regulatory factors 1 and 8 in human dendritic cells. Infect Immun. 2008;76:2138-2148. 
(36) Liu J, Guan X, Tamura T, Ozato K, Ma X. Synergistic activation of interleukin-12 p35 gene transcription by interferon regulatory factor-1 and interferon consensus sequence-binding protein. J Biol Chem. 2004;279:55609-55617.

(37) Bovolenta C, Driggers PH, Marks MS et al. Molecular interactions between interferon consensus sequence binding protein and members of the interferon regulatory factor family. Proc Natl Acad Sci U S A. 1994;91:5046-5050.

(38) Sharf R, Meraro D, Azriel A et al. Phosphorylation events modulate the ability of interferon consensus sequence binding protein to interact with interferon regulatory factors and to bind DNA. J Biol Chem. 1997;272:9785-9792.

(39) Eisenbeis CF, Singh H, Storb U. PU.1 is a component of a multiprotein complex which binds an essential site in the murine immunoglobulin lambda 2-4 enhancer. Mol Cell Biol. 1993;13:6452-6461.

(40) Goriely S, Cavoy R, Goldman M. Interleukin-12 family members and type I interferons in Th17mediated inflammatory disorders. Allergy. 2009;64:702-709.

(41) Longhi MP, Trumpfheller C, Idoyaga J et al. Dendritic cells require a systemic type I interferon response to mature and induce CD4+ Th1 immunity with poly IC as adjuvant. J Exp Med. 2009;206:1589-1602.

(42) Williams NK, Bamert RS, Patel O et al. Dissecting specificity in the Janus kinases: the structures of JAK-specific inhibitors complexed to the JAK1 and JAK2 protein tyrosine kinase domains. J Mol Biol. 2009;387:219-232. 


\section{Figure legends}

Figure 1: CD40L-induced IL-12p70 release requires complementary cytokine-induced JAK signals

CD $14^{+}$monocytes were cultured for 5 days in GM-CSF plus IL-4 to generate MoDCs. Thereafter, cells were washed twice and either activated immediately or rested in cytokinefree medium for an additional 48 hours (w\&r) before activation. Activation was performed for an additional 36 hours using a baby hamster kidney (BHK) cell line transfected with CD40L (CD40L) in a ratio of DCs to BHK cells of 20:1 (no cytokines were induced by the mocktransfected BHK line). The pan-JAK inhibitor Pyridone 6 was used at a non-toxic concentration of $500 \mathrm{nmol} / \mathrm{L}$. Cytokine concentrations: IL-4 (50 U/mL), IFN $\gamma(1000 \mathrm{U} / \mathrm{mL})$, GM-CSF (40 ng/mL). A. IL-12p70 release by non-rested DC, w\&r DCs; and effects of panJAK inhibition on non-rested DCs (means \pm SEM, $n=3-6, * * p<0.01$ vs. non-rested DCs). B. Synergism of CD40L and cytokines for IL-12p70 release from w\&r DCs (means \pm SEM, n=5$22, * \mathrm{p}<0.05 ; * * \mathrm{p}<0.01$ vs. CD40L). C. IL-12p70 formation by w\&r DCs activated with the indicated protocols in the presence and absence of Pyridone 6. Means \pm SEM, $n=11,{ }^{*} \mathrm{p}<0.05$, ** $\mathrm{p}<0.01$ vs. activation without inhibitor. D. Western Blots of phospho-JAK1,2,3 and -Tyk2 expression in MoDC activated with CD40L and cytokines for one hour. Representative of 3 experiments.

\section{Figure 2: siRNA inhibition of JAK family members}

Electroporation of day 5 DCs with scrambled (=negative control (scr)) or JAK-specific siRNAs. Cells were then rested for 48 hours in cytokine-free medium (w\&r). Thereafter, lysates were produced to analyse protein expression $(\mathbf{A}, \mathbf{E})$, or cells were washed and activated for an additional 36-hour period (as in Figure 1). Supernatants were then collected to measure IL-12p70 release from DCs using ELISAs. Shown are the means \pm SEM, (B-D): JAK1, JAK2, Tyk2 (n=8) and (F): JAK3 $(n=5),{ }^{*} \mathrm{p}<0.05 ; * * \mathrm{p}<0.01$ vs. scrambled siRNA.

\section{Figure 3: Regulation of IL-10 by cytokines and JAK1}

A. IL-10 release into supernatants of w\&r DCs 36 hours following activation with protocols as in Figure 1 (means \pm SEM, $n=11, * * p<0.01$ vs. CD40L). B. IL-10 release from w\&r DCs activated with the indicated protocols in the presence and absence of the pan-JAK inhibitor Pyridone 6. Means $\pm \mathrm{SEM}, \mathrm{n}=8, * * \mathrm{p}<0.01$ vs. activation without inhibitor. C. IL-10 release from MoDCs transfected with scrambled siRNA or siRNA for JAK1 48 hours prior to 
activation with CD40L and IFN $\gamma$. Means \pm SEM, $n=7, * \mathrm{p}<0.05$ vs. scrambled siRNA. D. Titration of the pan-JAK inhibitor increases IL-10 and reduces IL-12p70 release from w\&r DCs activated with CD40L+IFN $\gamma$ (3 individual experiments are shown). E,F. Production of IL-10 and IL-12p70 by w\&r DCs transfected with siRNA for IL-10 or scrambled siRNA 4 hours prior to activation. (E) Activation with $\mathrm{CD} 40 \mathrm{~L}$ and IFN $\gamma$ and (F) activation with CD40L alone. Means \pm SEM, $n=6, * * p<0.01$ vs. scrambled siRNA.

Figure 4: STAT1, IRF-1 and IRF-8 mediate complementary IFN- $\gamma /$ JAK effects on cytokine mRNA

Effects of siRNA inhibition of (A) STAT1 and STAT3 (n=9) and (B) IRF-1 and IRF-8 (n=5) on IL-12p70 and IL-10 secretion by DC activated with CD40L plus IFN- $\gamma$. Efficiency of siRNA inhibition is demonstrated by representative Western Blots. STATs are constitutively expressed; therefore siRNAs were used as for JAK inhibition (see Figure 2). IRFs are transcriptionally regulated; therefore activation protocols were added to w\&r DC 2 hours following electroporation. Supernatants were harvested 36 hours following activation in all protocols. Shown are the means \pm SEM, ${ }^{* *} \mathrm{p}<0.01,{ }^{*} \mathrm{p}<0.05$ vs. scrambled siRNA.

C, D: ChIP assays of DC lysates activated for 6 hours with the indicated protocols demonstrating JAK-dependent binding of STAT1 to the IL-10 promoter. IPs were performed using anti-STAT1 (C) or anti-IRF-8 mABs (D). Normalization of the PCR signals relative to the CD40L plus IFN- $\gamma$ protocol $=100 \%$. Means \pm SD of 4 experiments, $* p<0.05$ vs. CD40L plus IFN $\gamma$. As IRF-8 is regulated at the protein level (see Figure 5D), promoter binding was investigated comparing non-activated DCs and CD40L plus IFN- $\gamma$ activated DCs and could only be demonstrated for DNA fragments containing the $2^{\text {nd }}$ and $3^{\text {rd }}$ GAS site (D).

E: Real-time RT-PCR quantification of IL-12p35, IL-12p40 and IL-10 mRNA in w\&r DCs at 0, 3, 12 and 24 hours following activation with protocols as in Figure 1. Means \pm SD of copy numbers/ $\mu 1 \mathrm{cDNA}$ normalized to cyclophilin B expression, $n=3$.

Figure 5: JAK/STAT is the major CD40-complementing pathway induced by cytokines

A-D: EMSAs and supershift analyses of nuclear extracts of w\&r DCs activated with BHKCD40L, IFN- $\gamma$ or both or control medium for 1 hour up to 6 hours (E). No signal was observed with BHK-CD40L cells in the absence of DCs (not shown). Shown are the means \pm SEM $(\mathrm{C}, \mathrm{D} ; \mathrm{n}=3, * \mathrm{p}<0.05 ; * * \mathrm{p}<0.01$ vs. control $\mathrm{DCs})$ and 1 representative experiment (A, B). 
F,G: Time course of IRF-1 (F) and IRF-8 (G) protein expression in DC lysates (normalized for $\beta$-actin expression) following activation. One representative of 3 experiments is shown.

H: Quantitative Multiplex analysis of phospho-proteins in w\&r DC lysates activated for 1 hour with BHK-CD40L, BHK-CD40L plus IFN $\gamma$ or control medium. Means \pm SEM of 3 experiments are shown. I: Controls for $(\mathbf{H})$ : Protein expression in w\&r DC lysates activated for 1 hour with BHK-CD40L, BHK-CD40L plus IFN $\gamma$ or control medium (controls for A). Means \pm SEM of 3 experiments are shown. No changes in total protein levels were observed with the exception of IkB $\alpha$ (reduced in CD40L and CD40L $+\mathrm{IFN}-\gamma$ ).

Figure 6: JAK-dependent IL-12p70 release from human monocytes, B-cells and endothelial cells

Monocytes (A) and B-cells (B) were purified from peripheral blood of normal healthy volunteers in two sequential MACS separation steps (first $\mathrm{CD}_{14}{ }^{+}$enrichment, second negative $\mathrm{B}$-cell isolation from $\mathrm{CD}^{-} 4^{-}$fraction). Immediately following purification, cells were activated at a density of $10^{6} / \mathrm{ml}$ with the activation protocols as in Figure 1. (C) Human umbilical vein endothelial cells (HUVECs) were used as a primary culture after reaching confluence one week after isolation. Supernatants were analysed by ELISA 24-36 hours later. Means \pm SEM are shown, $n=16$ (monocytes), $n=7-10$ (B cells), $n=6$ (HUVECs). D. Inhibition of JAKs by the pan-JAK inhibitor Pyridone 6 blocked IL-12p70 formation in all three cell types tested. Means \pm SEM are shown, $n=3$ (monocytes and B-cells), n=6 (HUVECs). 

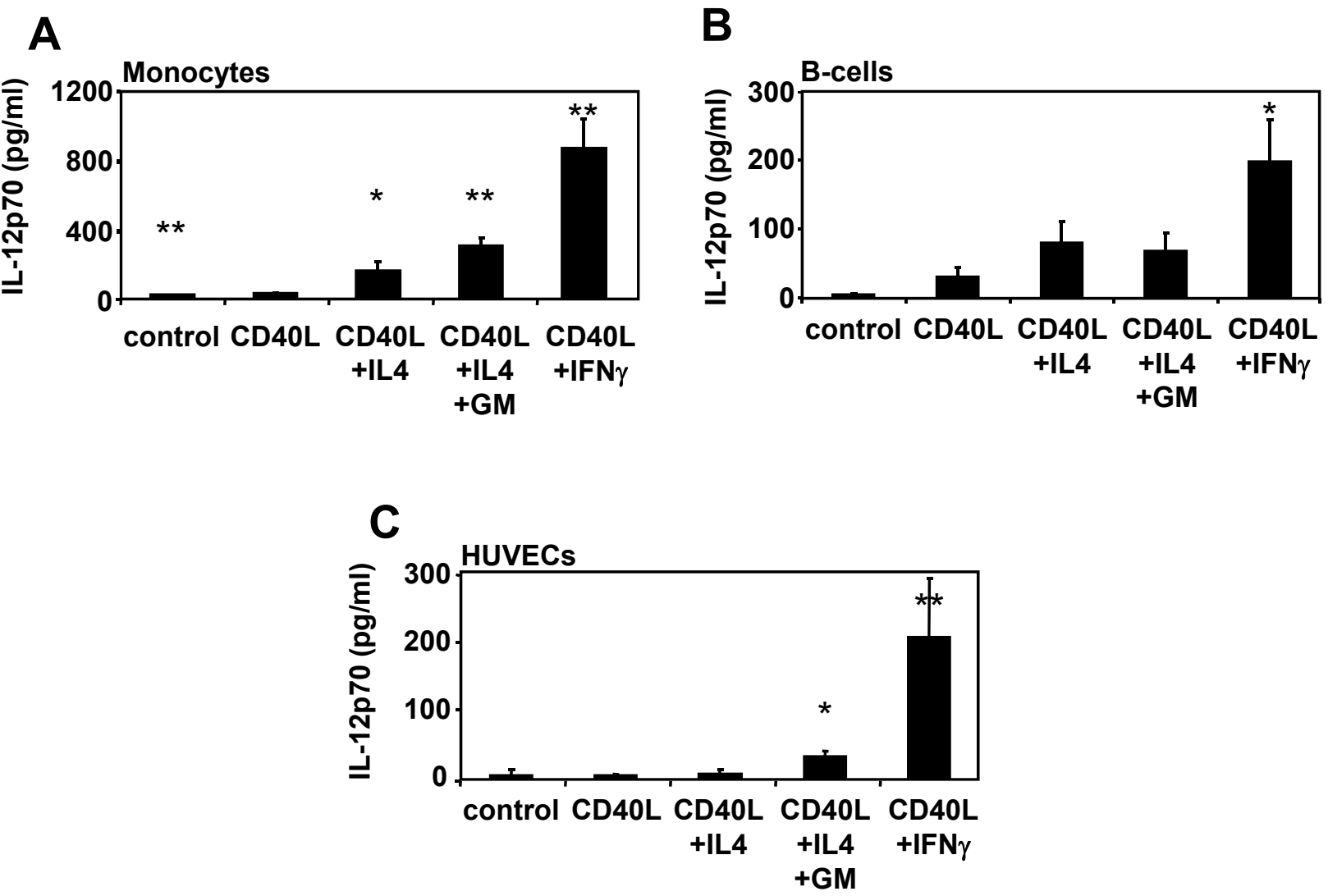

\section{D}

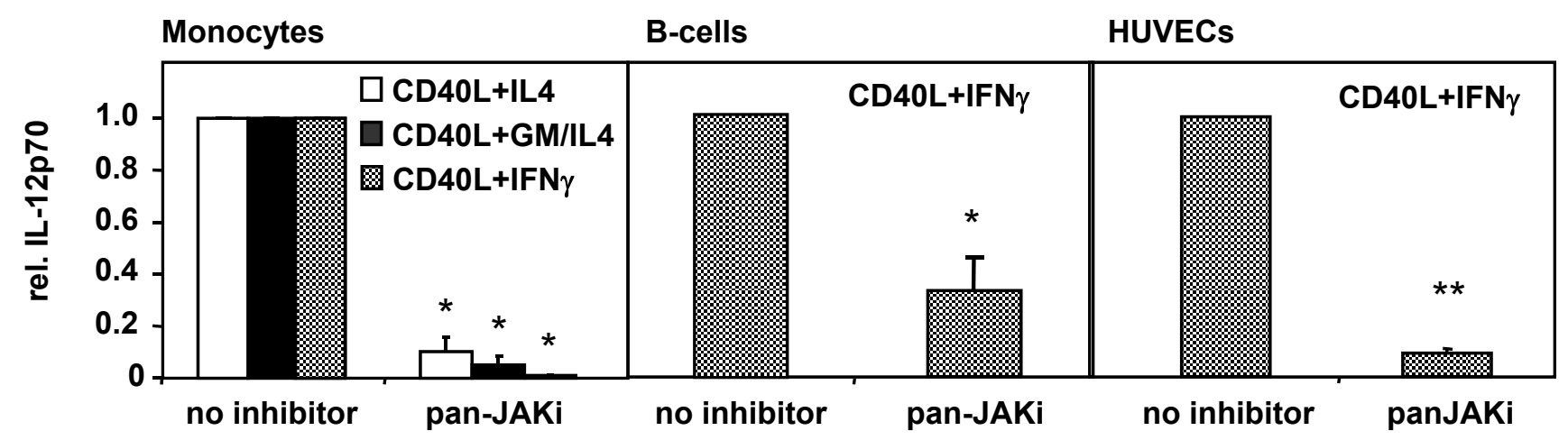


A

B

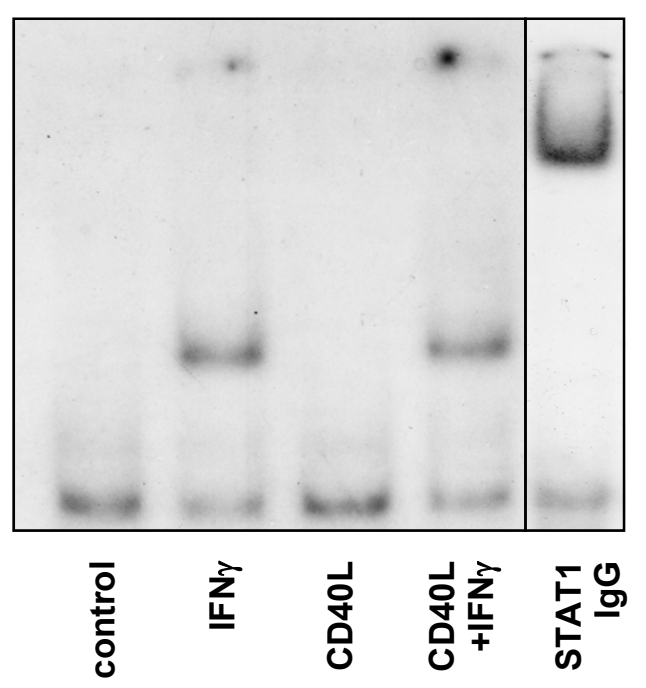

C
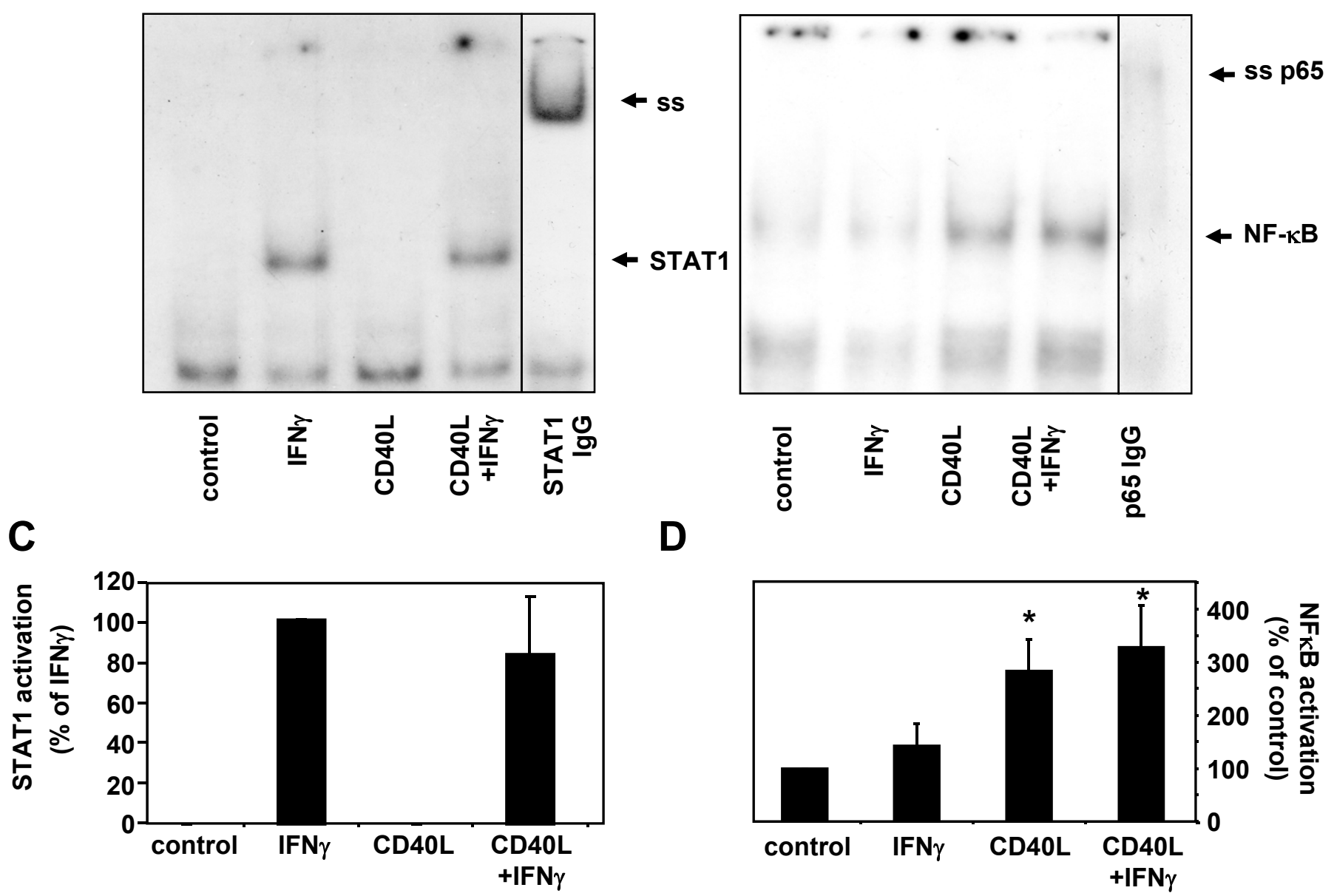

D

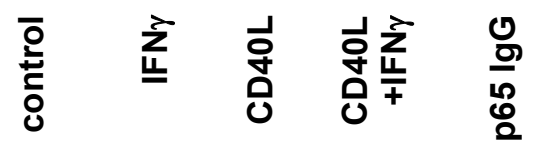

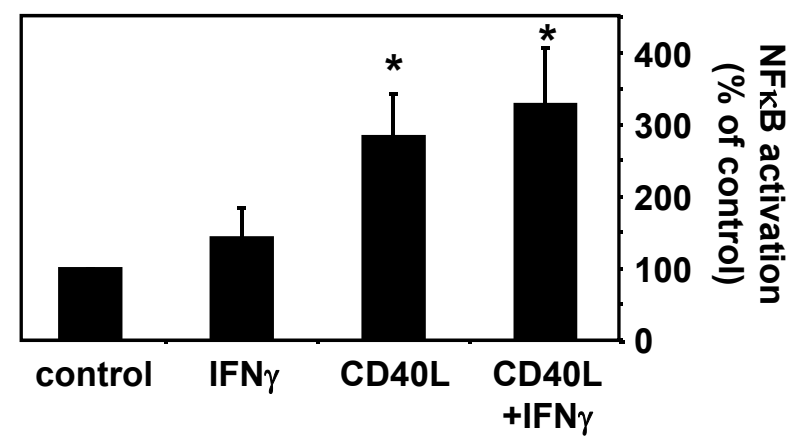

E

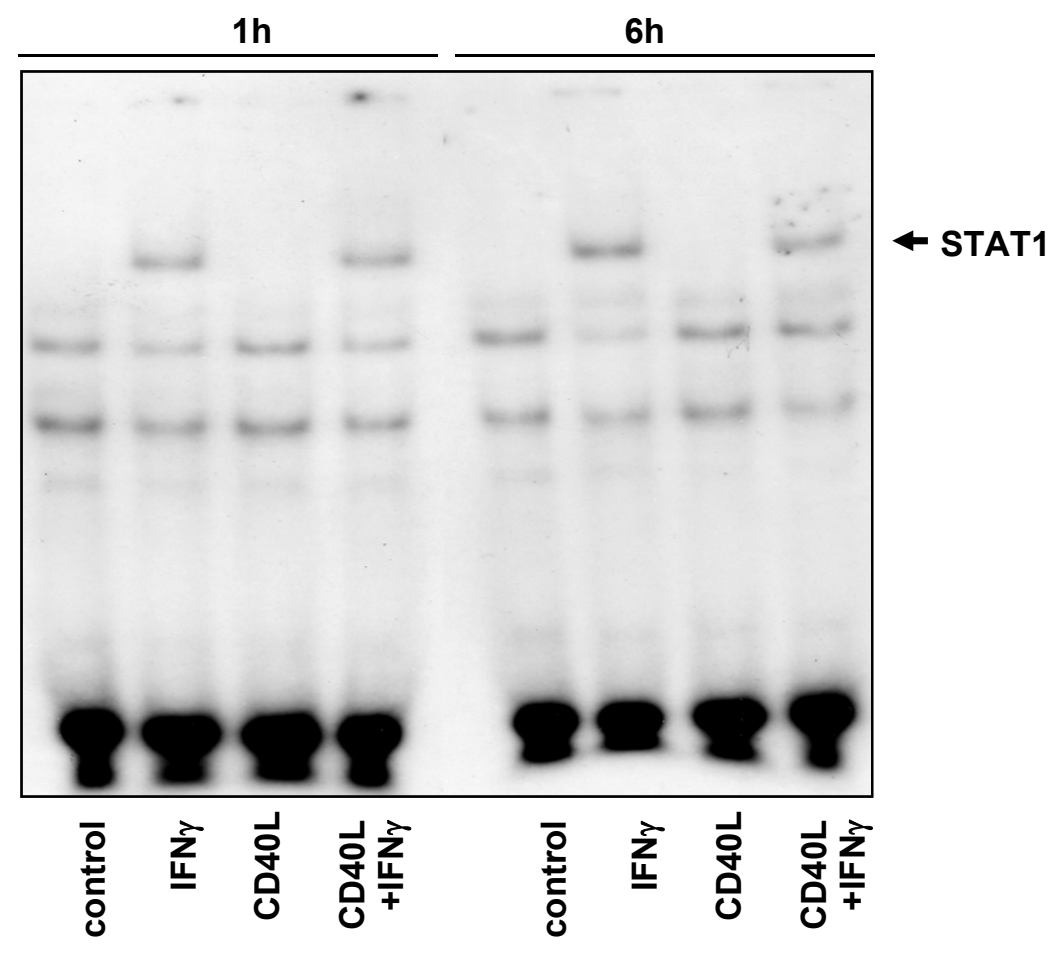


F

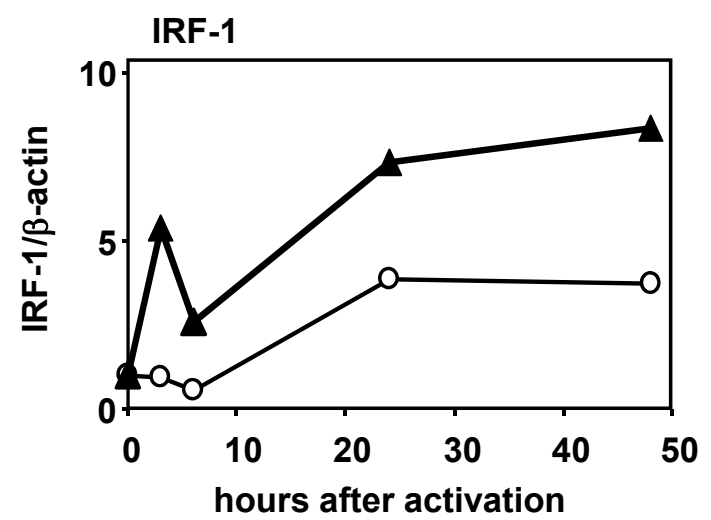

G

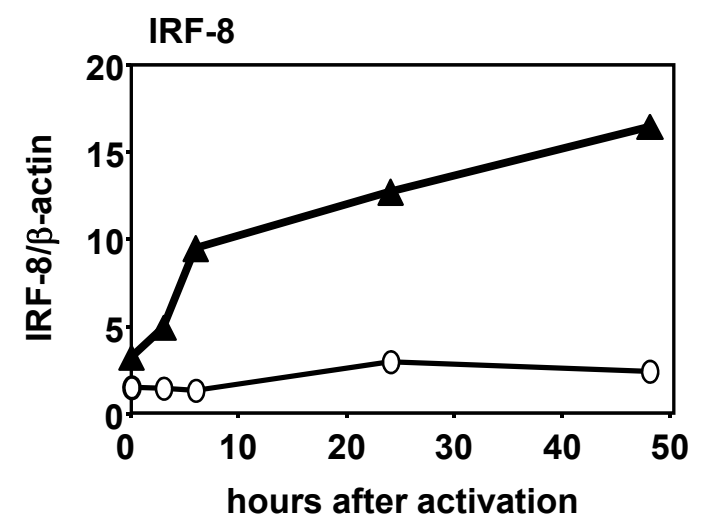

H -O-CD40L CD40L+IFN $\gamma$

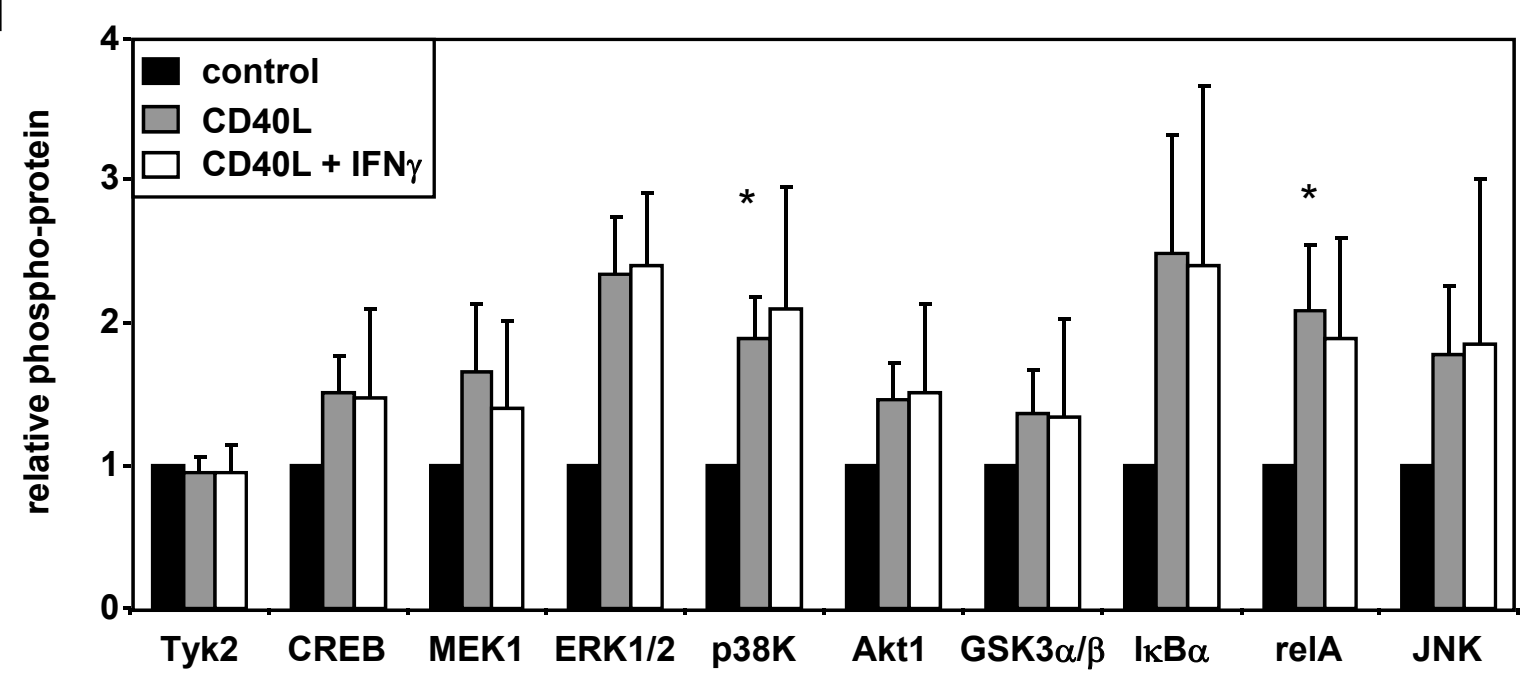

I

$$
\begin{array}{ll}
2 & \text { control } \\
& \square \text { CD40L } \\
& \square \text { CD40L + IFN } \gamma
\end{array}
$$

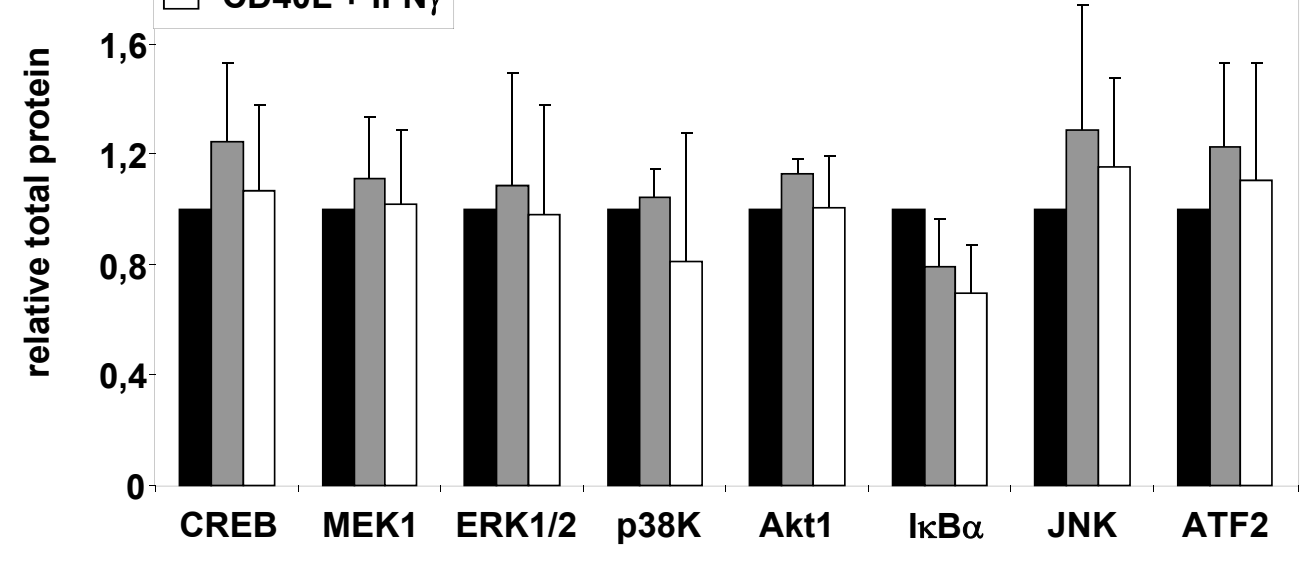


A

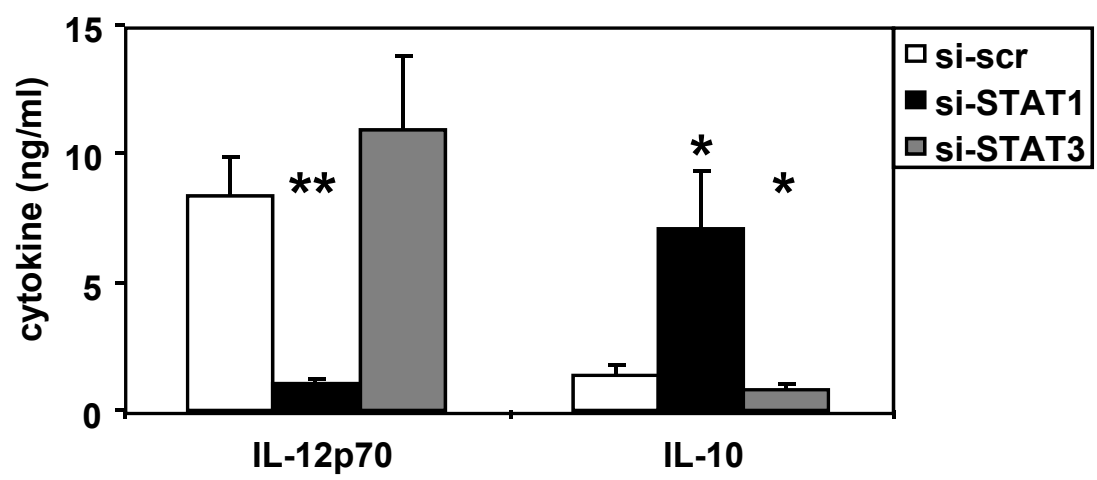

$\begin{array}{lll}\frac{5}{d} & \frac{m}{6} & \frac{1}{5} \\ \frac{1}{\omega} & \frac{1}{\omega} & \frac{1}{\omega}\end{array}$

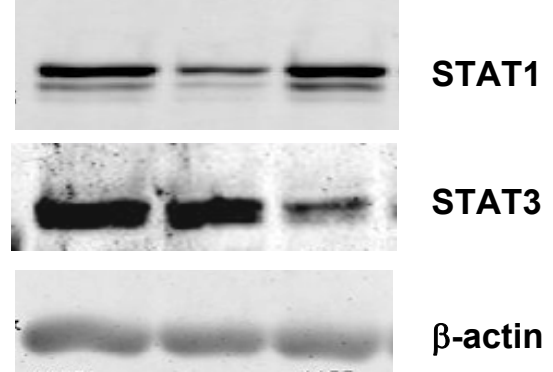

B
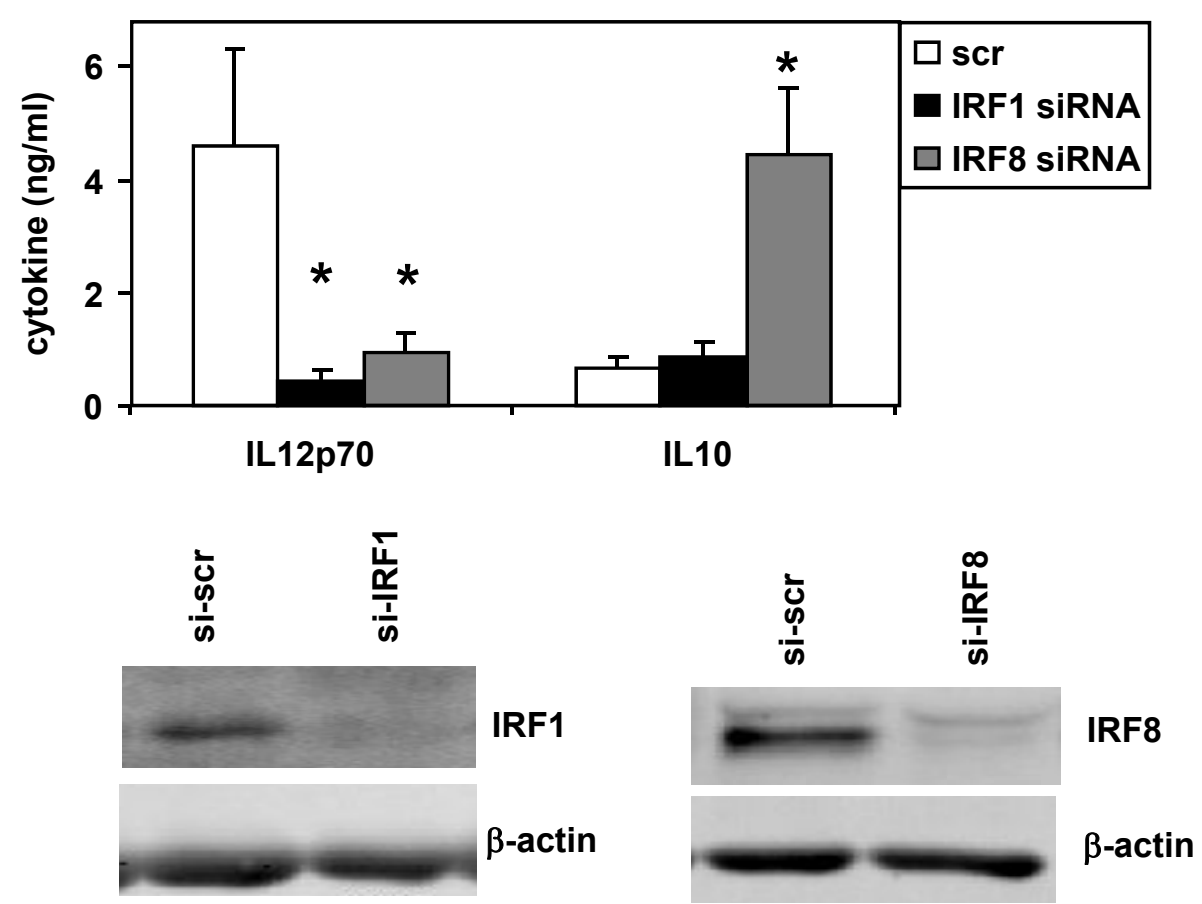
C

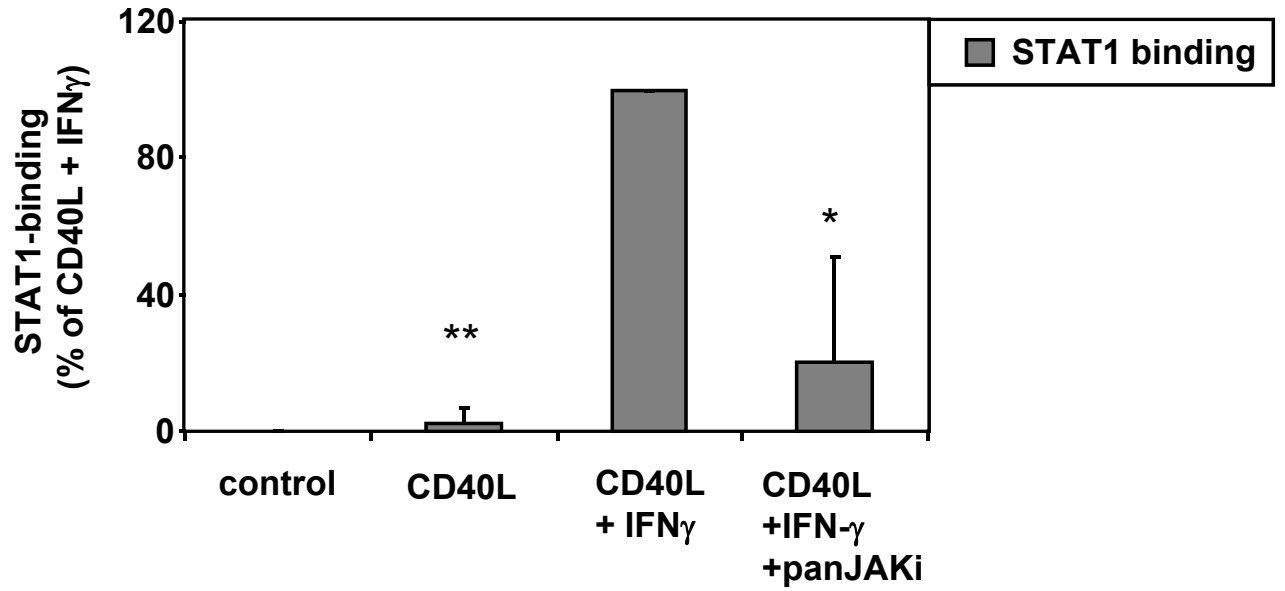

D

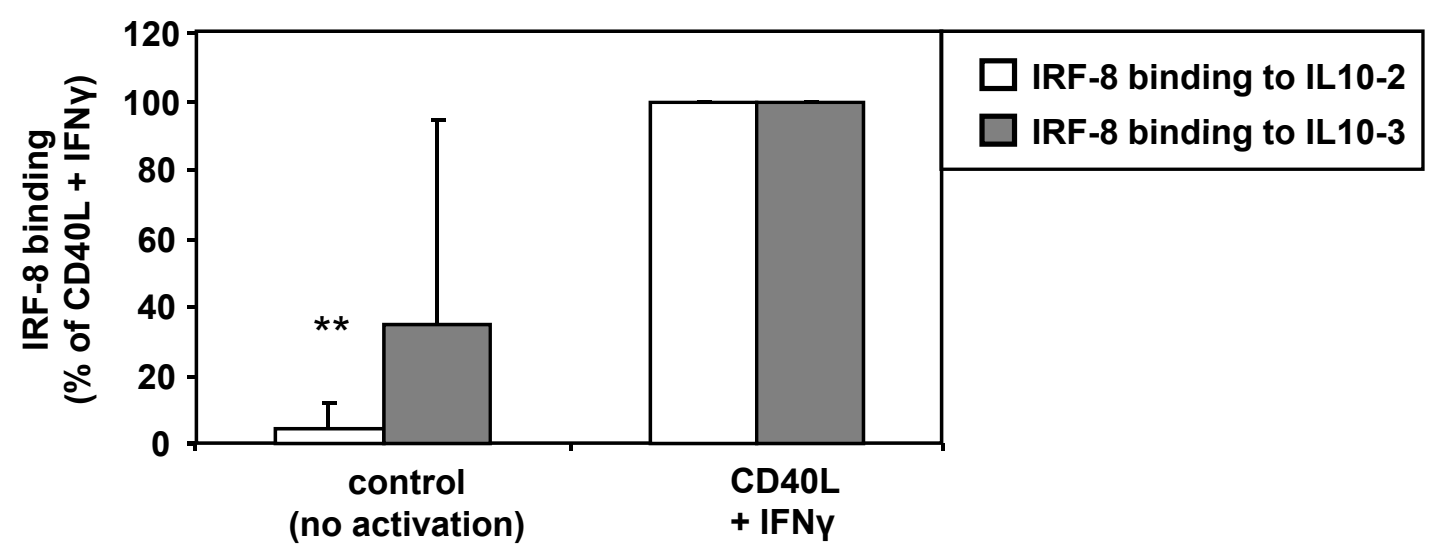

E
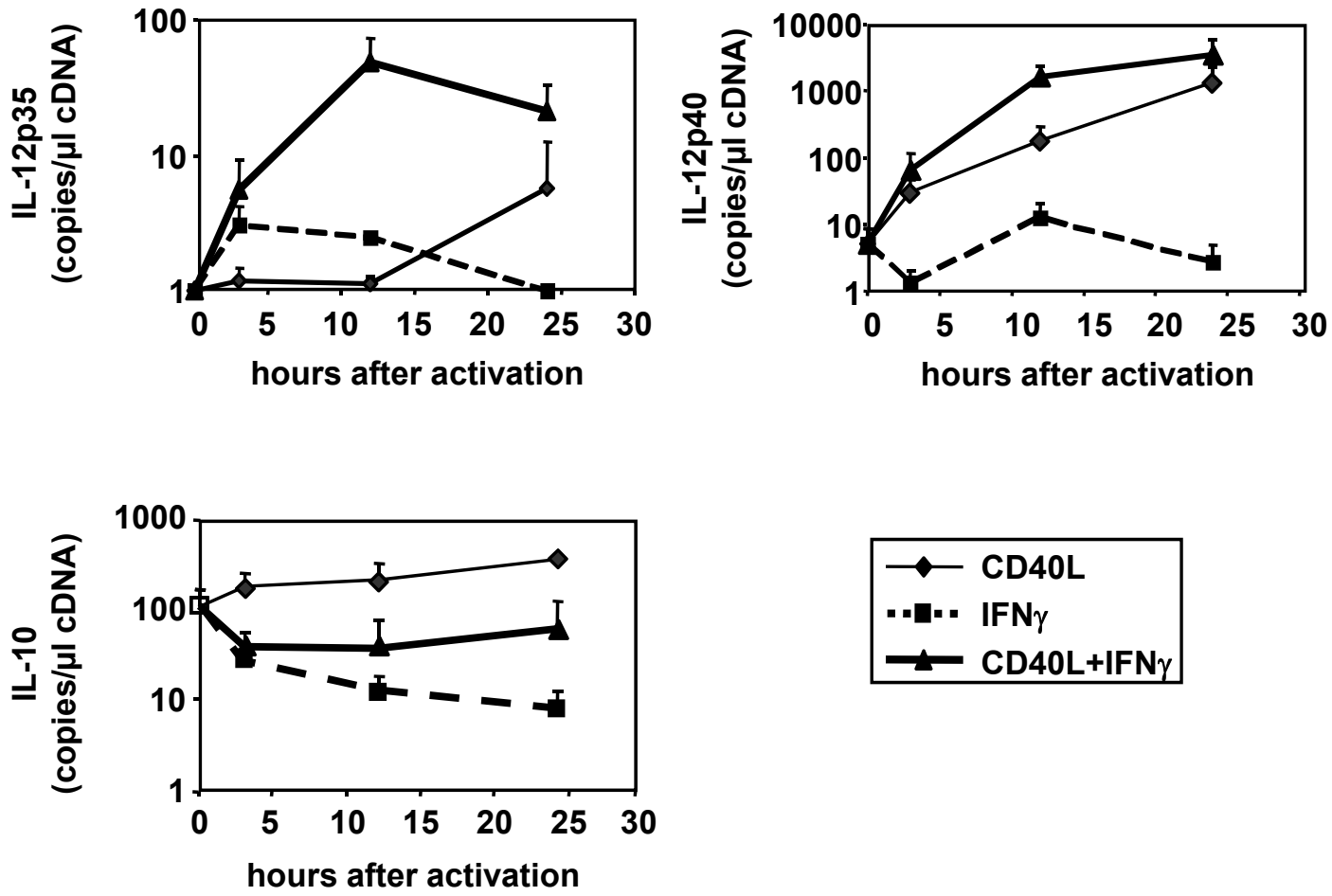
A
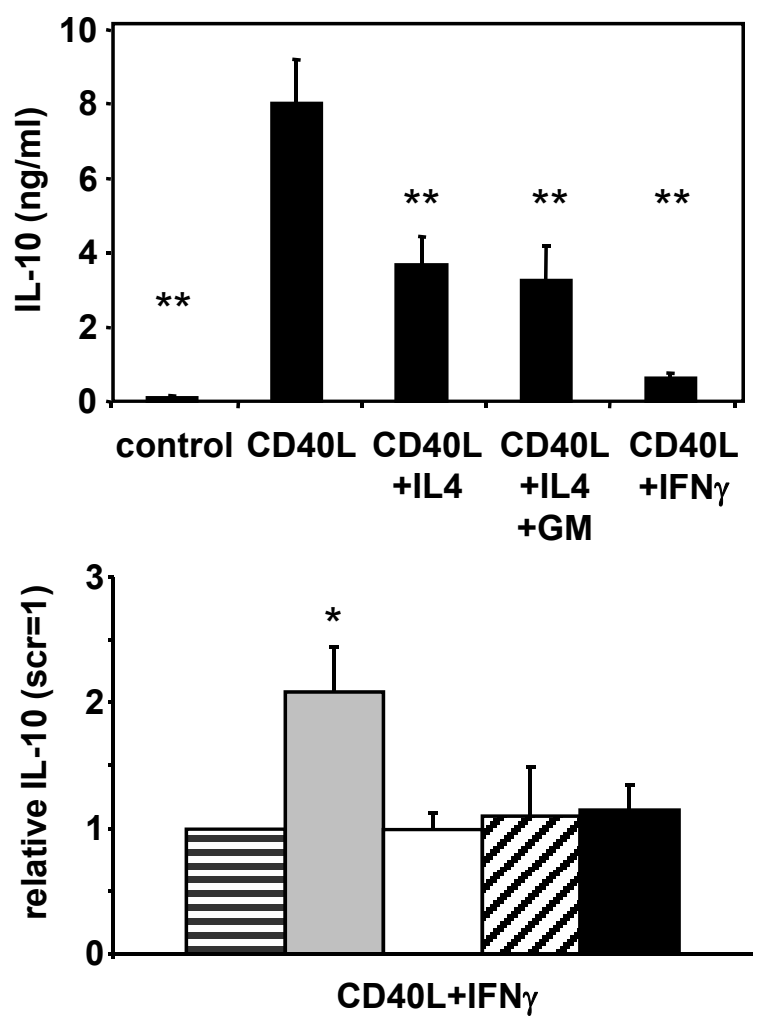

D

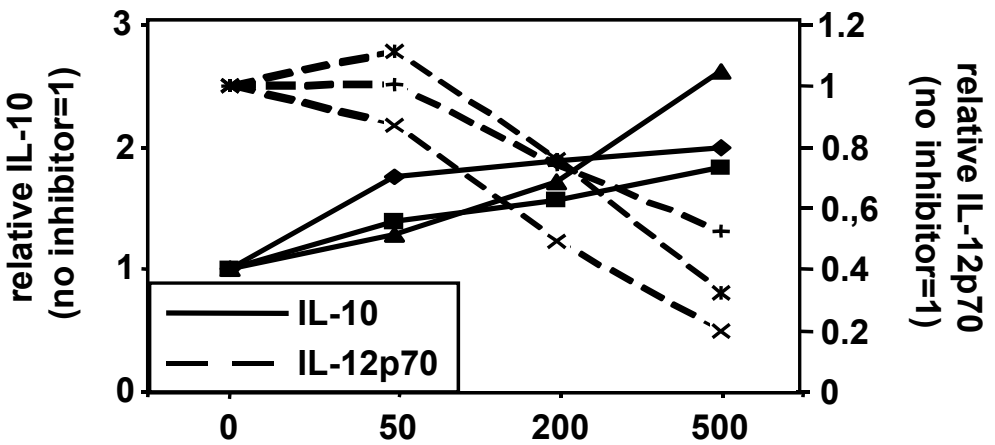

E pan-JAK inhibitor (nM)

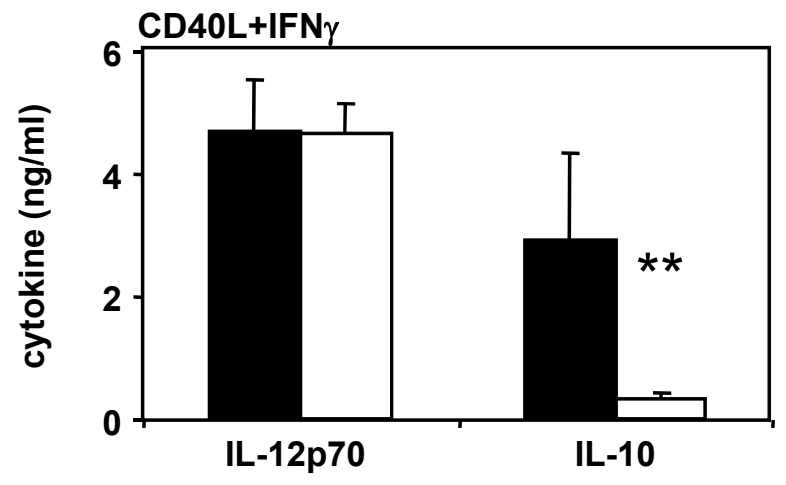

- scr siRNA

口 IL-10 siRNA
B

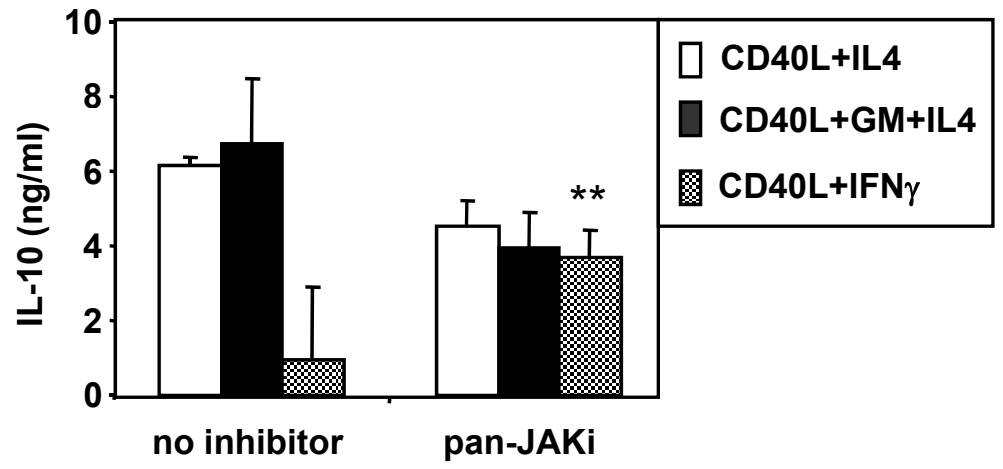

\section{日 scr SIRNA \\ JAK1 SIRNA \\ JAK2 SIRNA \\ JAK3 sIRNA \\ Tyk2 siRNA}

F

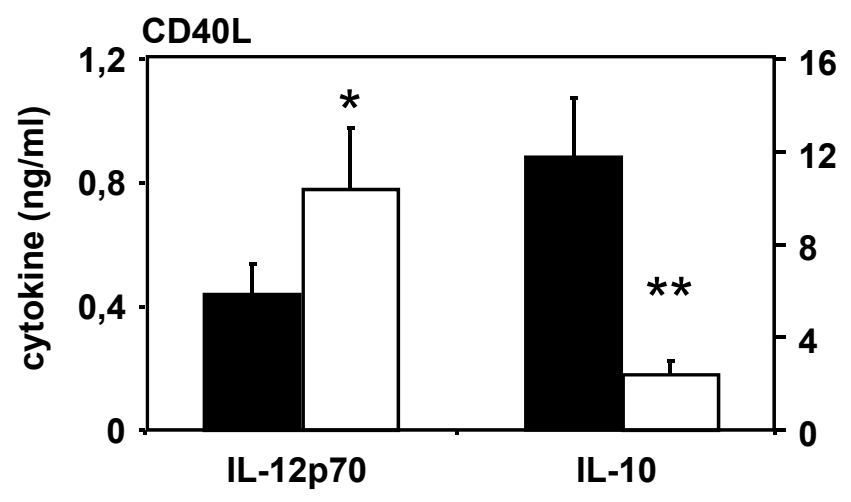

scr siRNA

$\square$ IL-10 siRNA 
A

\begin{tabular}{|c|c|c|}
\hline 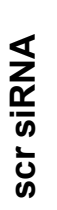 & 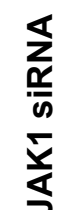 & 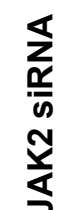 \\
\hline
\end{tabular}

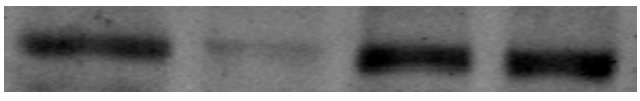

total JAK1

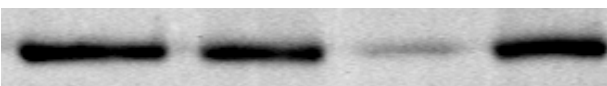

total JAK2

total Tyk2

$\beta$-actin

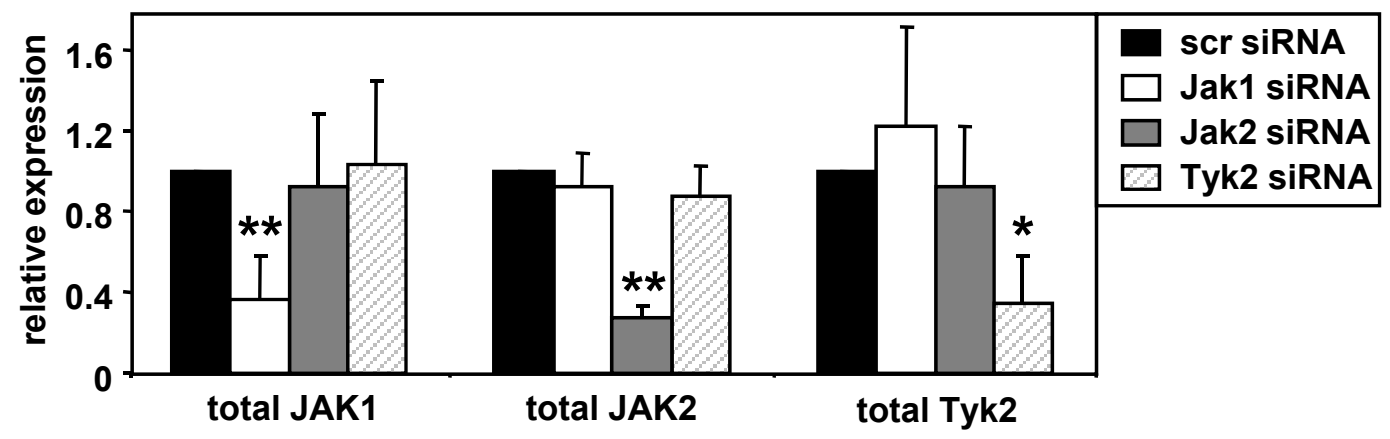

B
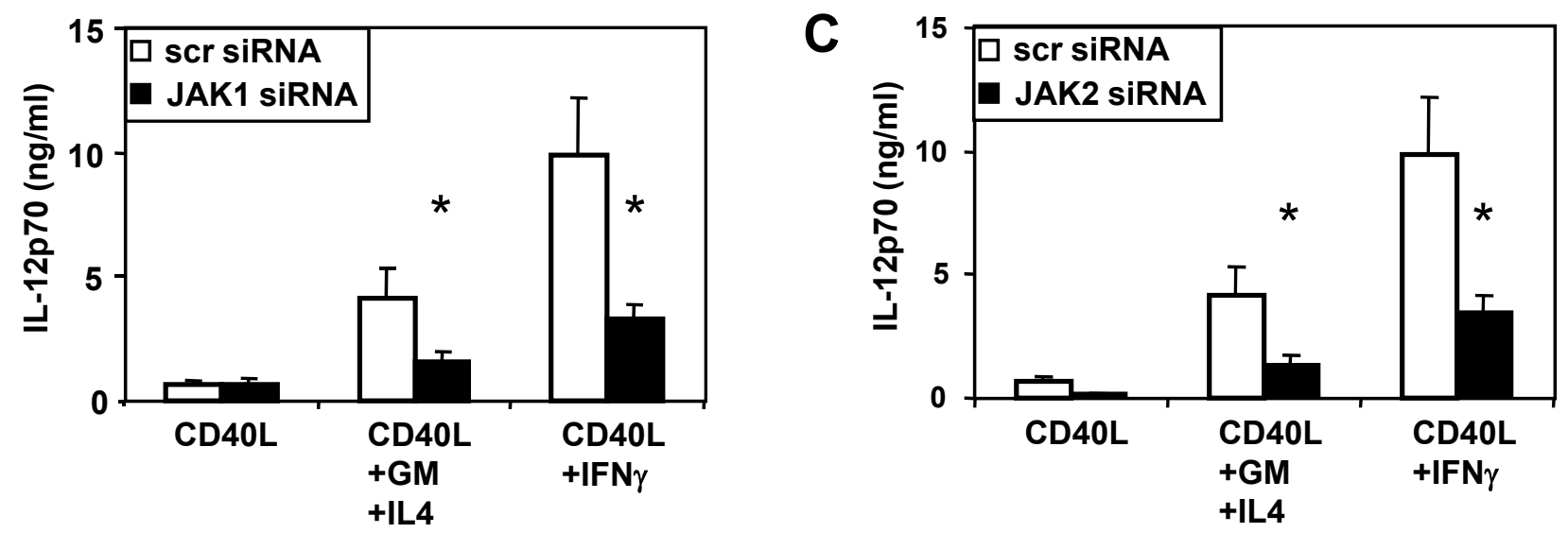

D

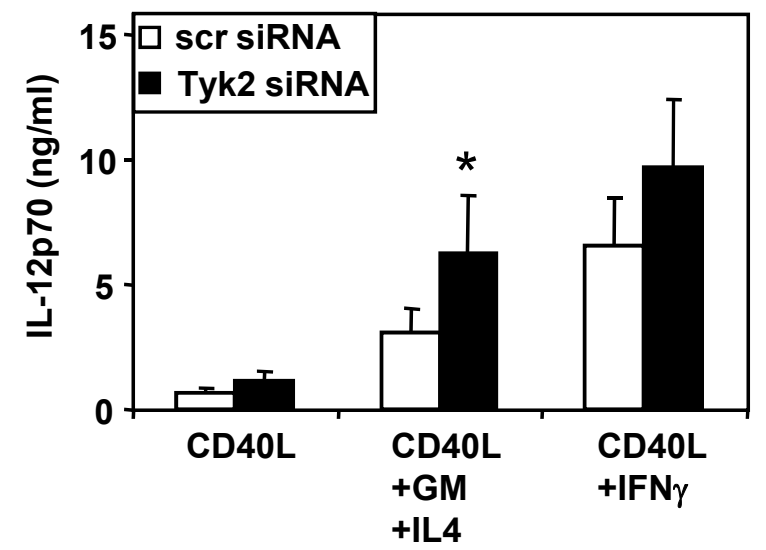


E
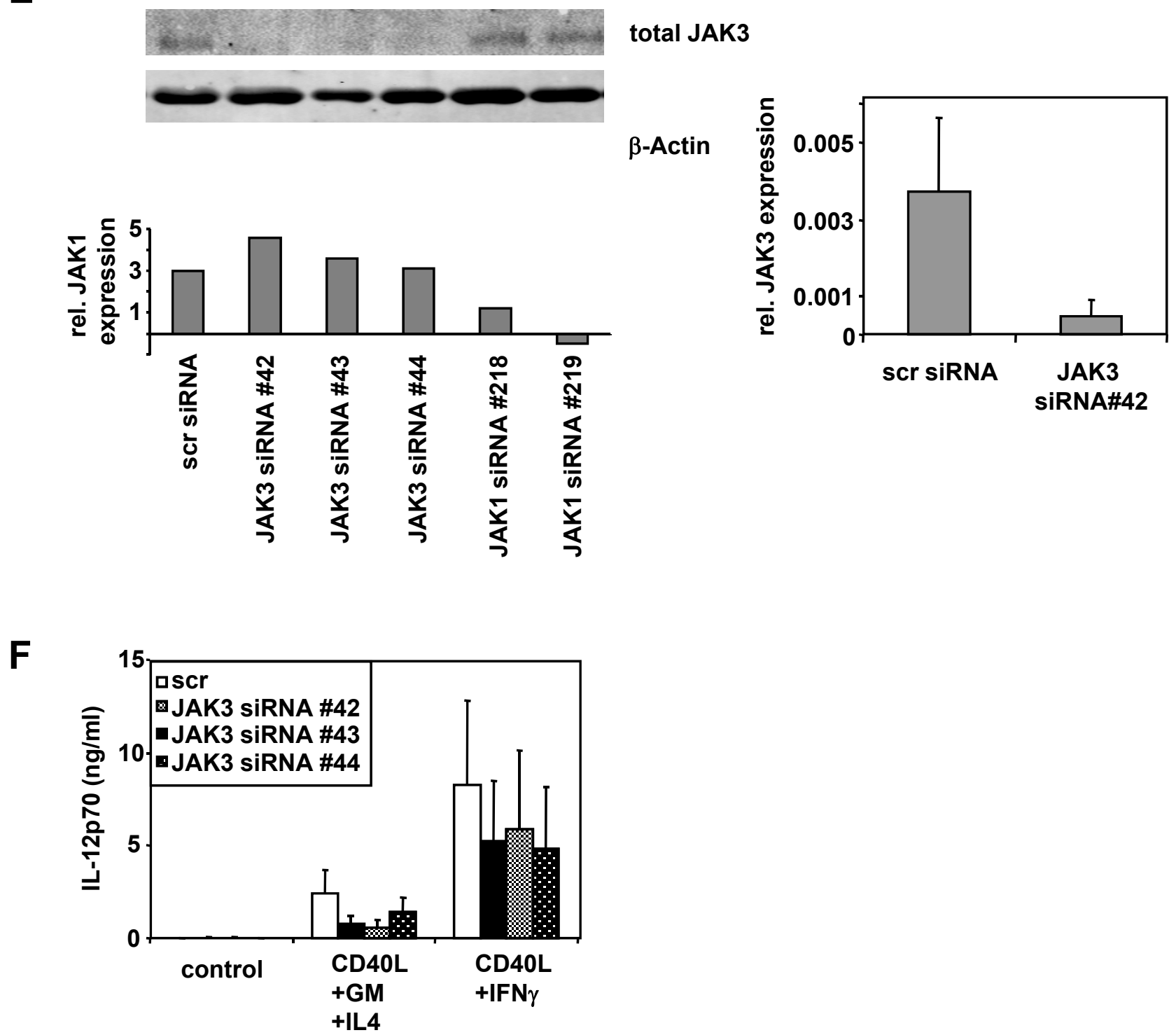
A

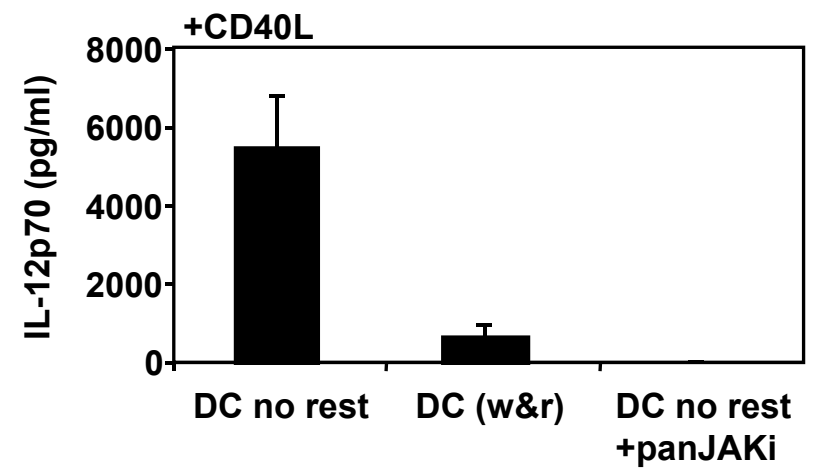

B

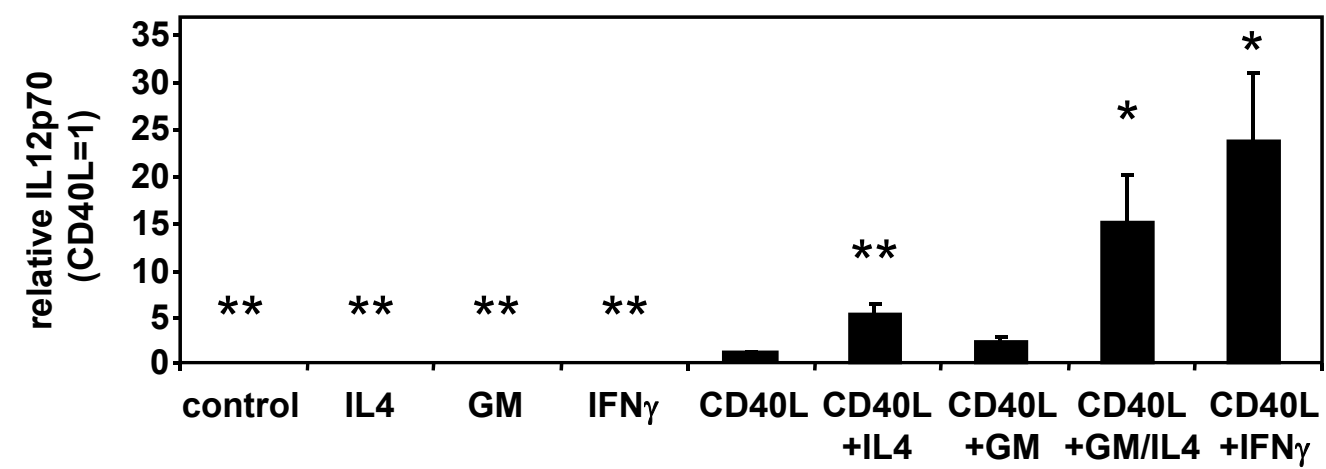

C

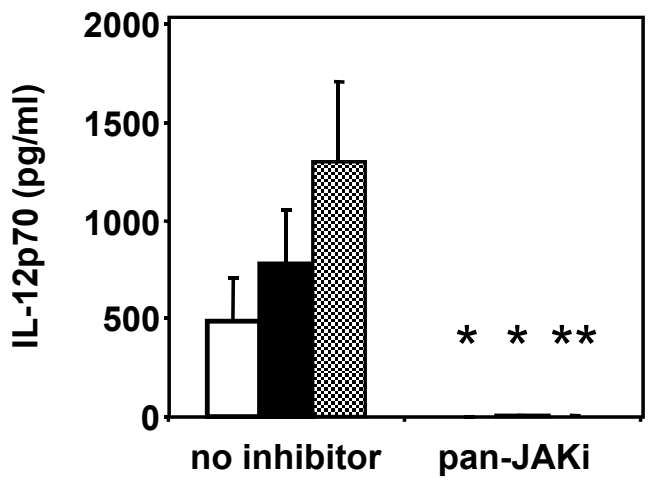

CD40L+IL4

CD40L+GM+IL4

圆 CD40L+IFN $\gamma$ 


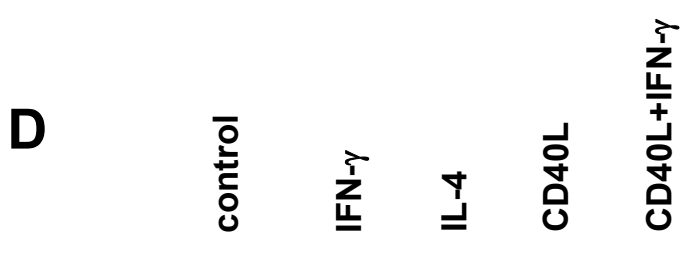

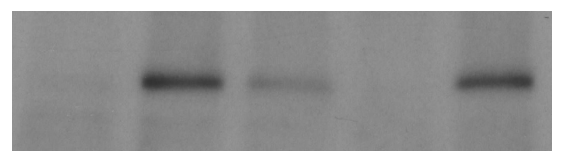

phospho-JAK1

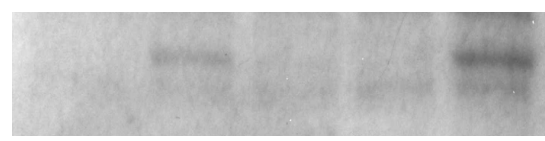

phospho-JAK2

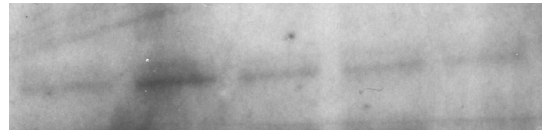

phospho-JAK3

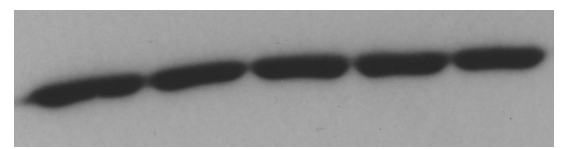

$\beta$-actin

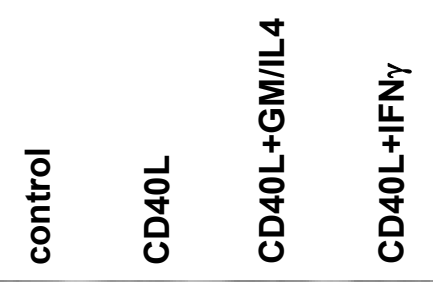

phospho-Tyk2

Tyk2 


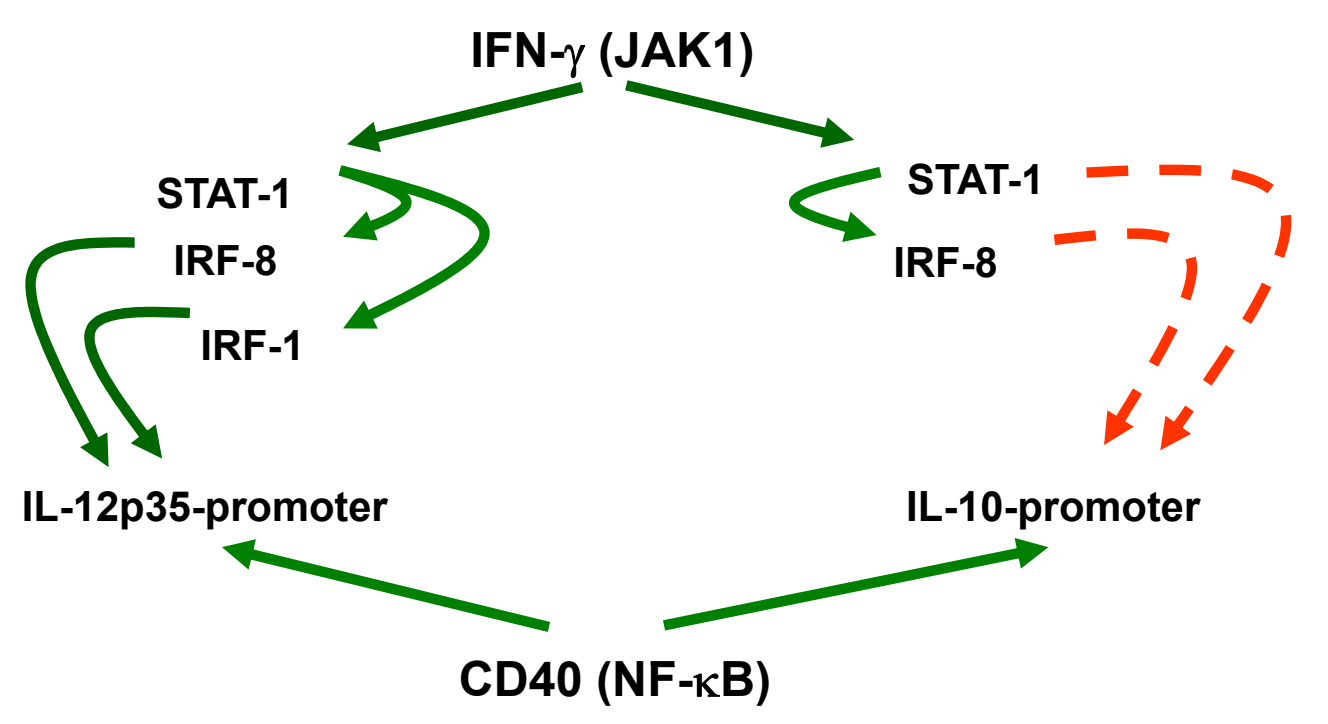

$\longrightarrow$ activation

$---\rightarrow \quad$ inhibition 